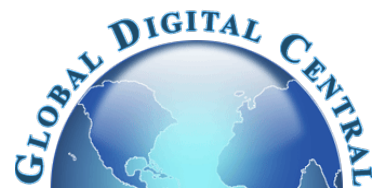

Frontiers in Heat and Mass Transfer

\title{
RESEARCH AND DEVELOPMENT OF LOOP HEAT PIPE - A REVIEW
}

\author{
Hao Guo ${ }^{\text {a }}$, Xianbing Ji ${ }^{\text {a,b1 }}$, Jinliang $\mathrm{Xu}^{\mathrm{a}, \mathrm{b}}$ \\ ${ }^{a}$ Beijing Key Laboratory of Multiphase Flow and Heat Transfer for Low Grade Energy Utilization, North China Electric Power University, Beijing \\ 102206, China \\ ${ }^{b}$ Key Laboratory of Power Station Energy Transfer Conversion and System (North China Electric Power University), Ministry of Education, Beijing \\ 102206, China
}

\begin{abstract}
With fast development of electronic devices, novel strategies of thermal management have been received great attention to dissipate high heat fluxes. As an efficient heat transfer device, loop heat pipe (LHP) provides ideal solution for such purpose. Even though LHP was invented nearly half-century ago, challenges still exist on its design, fabrication and operation. The objective of this paper is to present a thorough review on LHPs, paying more attention on the working principle, advantage and configuration. The review is performed in three aspects. First, the macroscopic operation characteristics such as start-up, temperature fluctuations and anti-gravity operation are described. Second, effects of various parameters or factors such as porous wick material, pore size and micro-structure on LHPs are reviewed. Third, new concept LHPs using biporous wick and wettability modification are discussed. Finally, perspective of LHPs is presented, which guides future research and development activities, from both fundamental and application point of view.
\end{abstract}

Keywords: loop heat pipe; porous wick; heat transfer; micro-nano structure

\section{INTRODUCTION}

With the development of micro-nano processing technology and equipment manufacturing, electronic devices are developing towards miniaturization and high integration. Sometimes, even more than 250,000 electronic components are included in a single integrated circuit. This increases the heat flux of electronic devices, which brings serious heat dissipation problems (high operating temperature) and restricts the development of electronic industry, because the service life and performance of electronic equipment have a direct relationship with its operating temperature. Studies indicate that when the temperature of a transistor is greater than $70{ }^{\circ} \mathrm{C}$, its reliability decreases by $50 \%$ for every $10^{\circ} \mathrm{C}$ increase (Belhardj et al. 2003). For high-performance chips, their local heat flux can be as high as $1000 \mathrm{~W} / \mathrm{cm}^{2}$ (Abdoli et al. 2014). If the heat cannot be removed in time, it will affect the safe and stability of high heat flux chips. Therefore, with advancement in the micro-nanoscale electronics systems, the demand for thermal management technology to dissipate the high amount of heat flux generated have become more rigorous.

Throughout the existing thermal management technology: traditional cooling methods, such as air cooling, cold plate technology, and phase change material technology are difficult to meet the cooling requirements. Liquid cooling heat transfer methods, such as jet and spray cooling, have strong heat transfer capacity, but due to the complex structure and low reliability, it is difficult to meet the size requirements of modern electronic equipment. So in the future, the mainstream idea to solve the thermal management problem of high heat flux heating elements is to develop a coupling thermal management system that comprehensively uses two or more cooling technologies. In addition, the future thermal management system should pay attention to the simplicity of structure and reliability of performance, avoid the introduction of external pumps and other power devices, to achieve silent and passive cooling effect.

As a phase change heat exchange device, heat pipe has the advantages of strong heat dissipation, small heat transfer temperature difference, compact structure, flexible installation, and no additional maintenance. It can transmit a large amount of heat through a small cross-sectional area for long distances without external power, which is recognized as one of the most effective passive heat transfer technologies and is widely used in the field of electronic cooling (Singh et al. 2019; Mirmanto et al. 2018; Faghri. 2012; Li et al. 2016; Krishna et al. 2017) and energy recovery (Srimuang et al. 2012; Yodrak et al. 2011) and space flight (Brenton et al. 2019). Gaugler (1944) and Grover et al. (1964) pointed out that the thermal conductivity of heat pipe is far more than any other metal materials. In 1965, Cotter et al. (1965) proposed a more comprehensive heat pipe theory, which laid the foundation for the research of heat pipe theory. According to the shape and structure, the heat pipe is mainly divided into three categories: (1) Flat heat pipe (Jouhara et al. 2009), its evaporator and condenser are usually flat type, which is convenient to connect with electronic chips and the heat sink of radiators, so it is mainly used in the field of electronic cooling (Zhou et al. 2016; Yang et al. 2015; Popova et al. 2006). (2) Gravity heat pipe (two-phase closed thermosiphon), it is similar to the flat heat pipe and relies on gravity to complete the cycle of working fluid, which is widely used in petrochemical field (Zhang et al. 2013; An et al. 2013; Zhang et al. 2010) and solar heat collectors (Nada et al. 2004; Hussein et al. 2003; Aung et al. 2013). (3) Loop heat pipe, is a more advanced temperature 
control device developed on the basis of traditional heat pipes. It was first proposed by Maidanik to solve satellite thermal control (Maydanik 2005), and has been successfully applied in the aerospace field. After the advent of LHP, it was highly valued as a valuable thermal control/management technology device.

LHP generally consists of five main parts: the evaporator, the condenser, the compensation chamber, the steam line and the liquid line. As the most critical component, evaporator integrates the capillary wick and the steam channel, as shown in Fig. 1. An important difference between LHP and conventional heat pipes is that LHP realizes the function of vapor-liquid separation in the phase change heat transfer process. For LHP, the porous wick in it has two important roles in the evaporator. On the one hand, due to the large thermal conductivity of porous wicks, when the evaporator is heated, the fluid near the evaporator bottom surface could absorb most of the heat, thereby controlling and reducing the heat leakage from evaporator to compensation chamber, which ensures that the vapor pressure and temperature in the evaporator are higher than the compensation chamber, that is, "heat lock"; On the other hand, the wicks provide large capillary force and maintains the liquid in wicks at a saturated state, ensuring that hot steam in the evaporator cannot enter the compensation chamber through the porous wick, that is, "water lock". For LHP, the heat flux could range at a large scope in the industrial applications, if the "heat lock" lose efficacy, the heat transfer from the evaporator to the compensation chamber will rise. So the temperature difference between the evaporator and the compensation chamber will be reduced, which results in a decrease in saturation pressure difference. On this situation the fluid inside the LHP stops flowing from the evaporator to the condenser and then LHP stops working. The temperature of the evaporator will grow sharply, causing equipment damage. The "water lock" and "heat lock" are closely linked. If the porous wick short of liquid medium, the vapor will easily enter the compensation chamber through wicks, so the "water lock failed" could result in "heat lock failed". These two functions of porous wicks ensure a stable circulation of working fluid from the steam line to the compensation chamber, and continuously transfer heat to the condenser and discharge it. It indicates that the porous wick plays a critical role in the LHP.

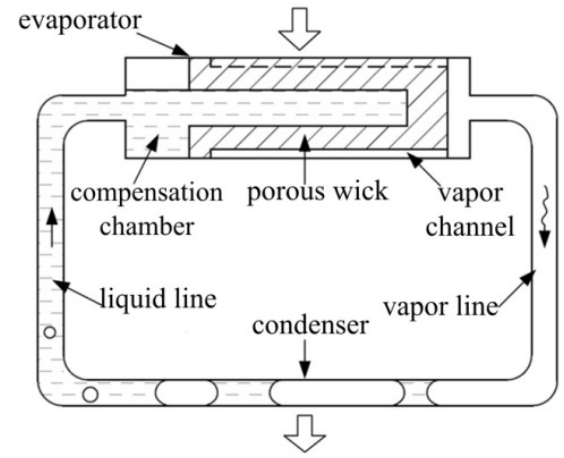

Fig. 1 Basic structure of loop heat pipe. (Maydanik 2005)

The LHP not only inherits the advantages of small heat transfer temperature difference of ordinary heat pipes and does not need external driving pump, but also has the following advantages compared with traditional heat pipes. The steam pipeline is separated from the liquid pipe line, which eliminates the viscous contact between the steam and liquid in the LHP, the inner surface of steam transportation pipe line is smooth without wick in it, which greatly reduces the resistance of steam along the pipe. Above two factors are helpful for LHP to possess high heat transfer efficiency and small internal thermal resistance. At the same time, because of split structure of LHP, it overcomes the requirements and limitations of the field position, and can arbitrarily arrange the gas and liquid pipe line according to the space situation. For example, the internal space for heat dissipation is small in the computer, so it can arrange the condenser away from the evaporator.

The basic working principle of the loop heat pipe is: When the evaporator is heated by a heat source, the working fluid in the evaporator will evaporate, and the generated steam will enter into the condenser through the steam pipe. Then the steam in the condenser is condensed into liquid and returned to the compensation chamber through the liquid line. The liquid in the compensation chamber is sucked by the porous wicks and then enters the evaporator for secondary evaporation, thus completing a heat exchange cycle. It can be seen that the working principle of LHP is similar to that of conventional heat pipe. Both of them are phase-change heat transfer processes driven by capillary forces, the difference is that the LHP separates the relative movements of the steam and liquid in the heat pipe, which well solves the conflict and contradiction between steam and liquid in the flow aspects.

\section{STRUCTURE TYPES AND THERMAL CYCLE OF LHP}

\subsection{Structure Types}

In heat pipes, the shapes of the evaporator are varied, when the LHPs were first designed, the shapes of evaporators were cylindrical (Singh et al. 2014; Wang et al. 2019; Bai et al. 2009) (see Fig. 2). But in practical applications, the heat transfer surface was always flat. Therefore, it is necessary to use an intermediate conversion heat conduction to connect the cylindrical evaporator and the heat exchange surface, which causing an increase in thermal resistance.

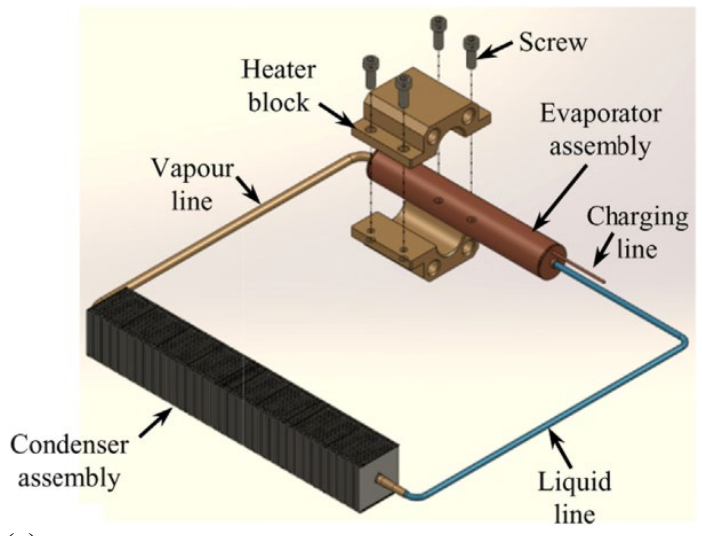

(a)

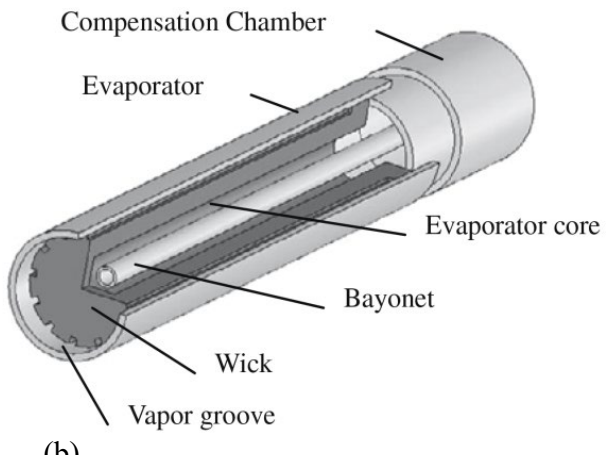

(b)

Fig. 2 Cylindrical evaporator and LHP, (a) (Singh et al. 2014), (b) (Bai et al. 2009).

Later, a flat-plate evaporator was created that was easily integrated with the heat source (Tian et al. 2019; Wang et al. 2012; Maydanik et al. 2011; Becker et al. 2011; Ji et al. 2017) (see Fig. 3). By contrast, cylindrical evaporators are easy to seal against leaks, internally avoiding 


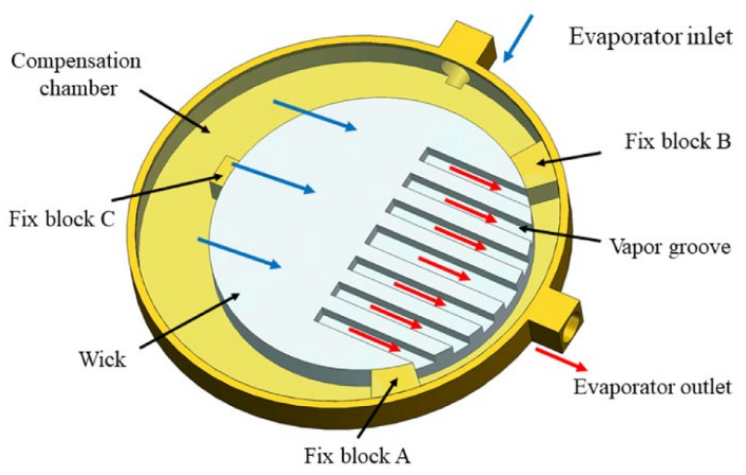

(a)

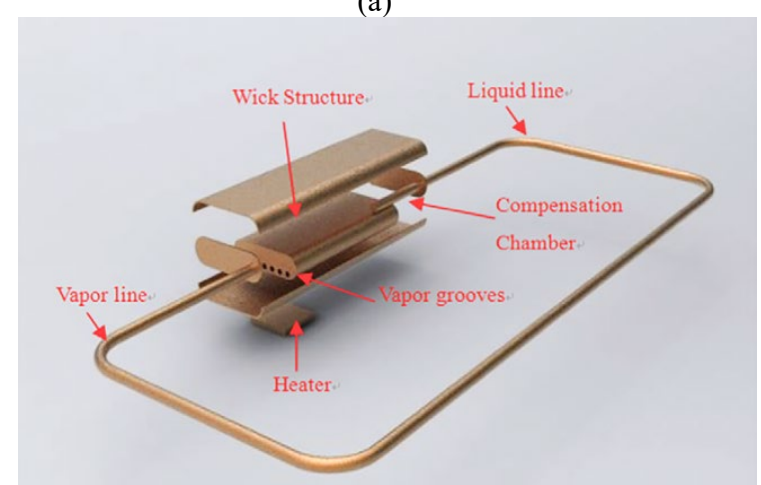

(b)

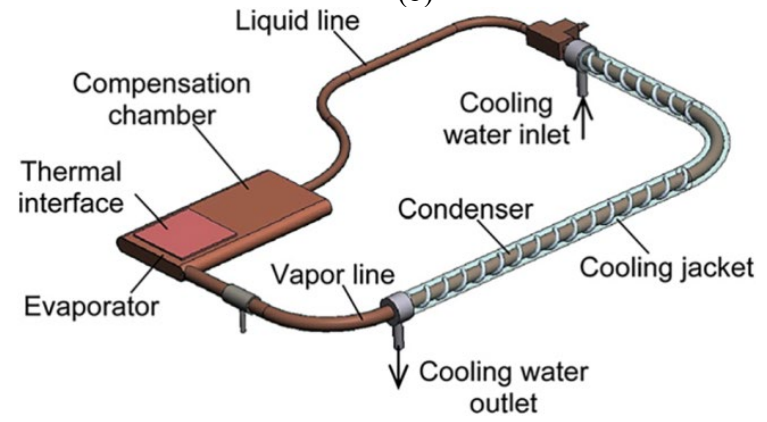

(c)

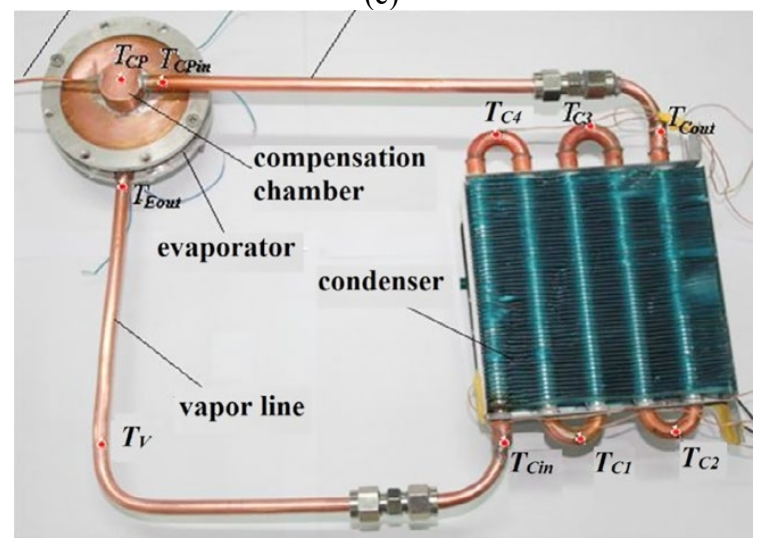

(d)

Fig. 3 Flat evaporator and LHP, (a) (Tian et al. 2019), (b) (Wang et al. 2012), (c) (Maydanik et al. 2011), (d) (Ji et al. 2017).

vapor from evaporator to compensation chamber and externally preventing air from ambient to evaporator. They are also structurally stronger than flat evaporator, particularly for high pressure working fluids like ammonia. However, flat evaporators unlike cylindrical shape that needs metal interface for attachment with the flat surfaces, so they generally provide low thermal resistance from heat source to evaporator surface and are very space conservative. In terms of comprehensive comparison, flat disk shape is one of optimum evaporator shape. Compared to the cylindrical and ordinary flat shape evaporator, the advantages of the flat disk shape evaporator are shown in two aspects: on the one hand, it has the advantages of a flat evaporator, which can be in close contact with the heat exchanger, reducing the contact thermal resistance. On the other hand, because the side is cylindrical, so it can resist the pressure of high pressure or high vacuum, and can meet the requirements of different working fluids and workloads. In addition, when the evaporator is circular, it is a center symmetrical structure. Whether it is for steam overflow or liquid replenishment there is little fluid retention in the evaporator during the operation process of LHP. Therefore, the overall temperature uniformity of the evaporator is better than that of the ordinary flat evaporator (Singh et al. 2007).

\subsection{Thermal Cycle of LHP}

During the operation of the LHP, the pressure, temperature of the working fluid continuously change with the change of the circulation position. Fig. 4a shows the pressure-temperature diagram of the stable operation of the LHP. The circulating path of working fluid in the system is shown in Fig. 4b. The processes are as follows:

$1 \rightarrow 2$ : The steam vapor-phase on the meniscus side of the capillary wick is in the saturated state 1 and flows along the steam channel to the evaporator outlet. During the process, the steam continues to be heated and the pressure is reduced by overcoming the flow resistance.

$2 \rightarrow 3$ : The steam in the state 2 flows along the steam line to the condenser inlet, and the process is considered as isothermal flow in the ideal state, but the pressure continues to drop to the state 3 .

$3 \rightarrow 4$ : The superheated steam enters the condenser, being cooled and releasing heat, and becomes saturated state 4 .

$4 \rightarrow 5$ : The saturated working fluid is cooled to a liquid state, reaching the condenser outlet, and becomes the supercooled state 5 .

$5 \rightarrow 6$ : The supercooled working fluid reaches the inlet of the compensation chamber along the liquid line. The process is approximately considered to be isothermal and reaches the state 6 .

$6 \rightarrow 7$ : The working fluid enters the compensation chamber. Due to the existence of heat leakage, the working fluid is heated to the saturated state 7 .

$7 \rightarrow 8$ : The saturated working fluid enters the evaporator under the action of capillary force and continues to be heated to superheat state 8 . Due to the duration of the state is short, the boiling does not occur.

$8 \rightarrow 1$ : The working fluid in state 8 evaporates in the capillary wick, and the pressure rises to state 1 .

Because the working fluid will be hindered by various resistances during the movement in the LHP, the circulation power needs to overcome the pressure loss during the circulation, that is, the dynamic conditions: For a proper loop operation, the primary wick in the evaporator must have a sufficient capillary pumping head to overcome pressure losses in the loop components (Ku 1999). The total pressure drop in the system is the sum of frictional pressure drops in the evaporator grooves, the vapor line, the condenser, the liquid line, and the evaporator wicks, plus static pressure drop due to gravity (Launay et al. 2007):

$$
\begin{gathered}
\Delta P_{c}=\frac{2 \sigma}{r_{e}} \geq \Delta P_{\text {total }} \\
\Delta P_{\text {tot }} \geq \Delta P_{\text {groove }}+\Delta P_{v}+\Delta P_{\text {cond }}+\Delta P_{l}+\Delta P_{w}+\Delta P_{g}
\end{gathered}
$$

where $\Delta P_{\mathrm{c}}, \Delta P_{\mathrm{tot}}, \Delta P_{\text {groove }}, \Delta P \mathrm{v}, \Delta P_{\text {cond }}, \Delta P_{\mathrm{l}}, \Delta P_{\mathrm{w}}$, and $\Delta P_{\mathrm{g}}$ are the capillary pressure, total pressure drop, channel pressure drop, steam line pressure drop, condensation pressure drop, liquid line pressure drop, pressure drop in wick and gravity pressure drop respectively. $\sigma$ and $r_{\mathrm{e}}$ are the surface tension of the working fluid and the effective pore diameter of the wick, respectively. 
In addition, from the perspective of thermal cycle, the cycle of the working fluid also needs to meet the difference between saturation pressures:

$$
\begin{gathered}
\Delta p_{\text {sat }}=p_{\text {sat }}\left(T_{v}\right)-p_{\text {sat }}\left(T_{c p}\right) \geq \Delta p_{e x} \\
\Delta p_{e x}=\Delta p_{\text {tot }}-\Delta p_{w}
\end{gathered}
$$

where $\Delta P_{\text {sat }}$ is the saturation pressure difference between the evaporator and the compensation chamber; $T_{\mathrm{v}}$ and $T_{\mathrm{cp}}$ are the steam temperature in the capillary wick and the temperature in the compensation chamber; $P_{\text {sat }}$ $\left(T_{\mathrm{v}}\right)$ and $P_{\mathrm{sat}}\left(T_{\mathrm{cp}}\right)$ are the saturation pressures corresponding to $T_{\mathrm{v}}$ and $T_{\mathrm{cp}}$, respectively; $\Delta P_{\mathrm{ex}}$ is the total pressure drop excluding the capillary pressure drop $\Delta P_{\mathrm{w}}$. The thermal analysis of circulating power in heat pipes has also been mentioned in other papers (Zhang et al. 2011; Ambirajan et al. 2012). The above four equations well describe the relationship among capillary pressure, steam pressure and pressure drop of each part.

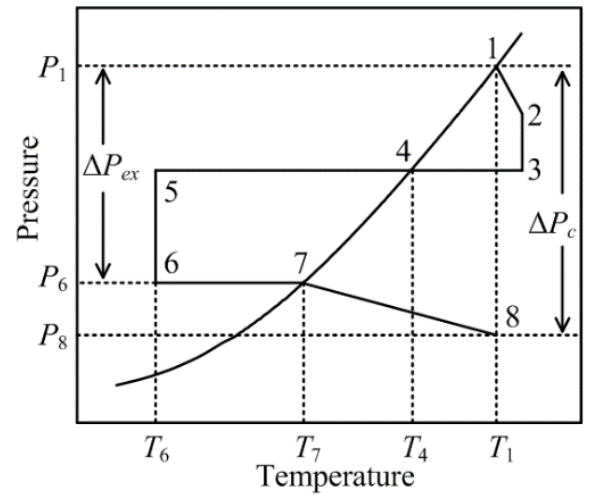

(a) Thermal cycle of LHP

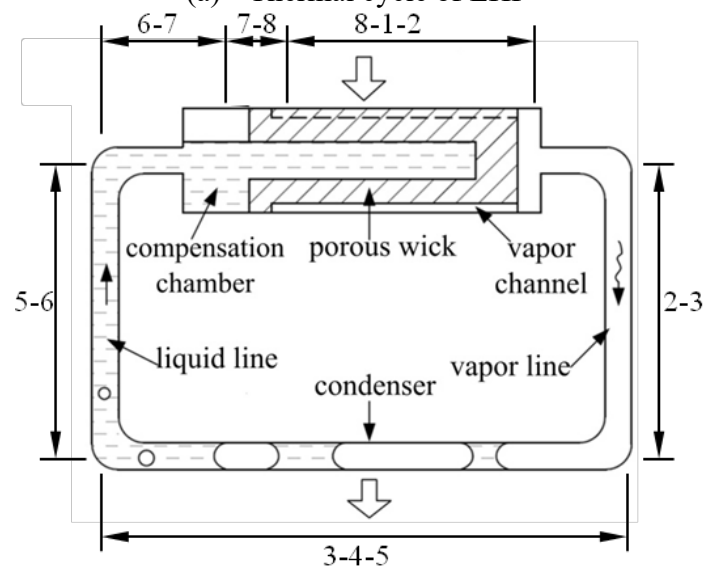

(b) Circulating path of working fluid

Fig. 4 (a) Schematic diagram of pressure-temperature for stable operation of LHP. (Maydanik 2005), (b) The circulating path of working fluid in the system.

\section{OPERATIONAL CHARACTERISTICS OF LHP}

\subsection{Start-up Performance of LHP}

In a LHP, start-up performance refers to four characteristics of heat pipe during start-up process: (1) Start-up time, which refers to the time taken by the evaporator from being heated to the temperature of the evaporator tending to be stable. When the heat was transferred to the evaporator, the working fluid in the wick will absorb the heat and evaporates, then releases the heat in the condenser. The shorter the start-up time, the better the heat transfer performance of the heat pipe is. (2) Start-up temperature, which refers to the temperature of the evaporator on stable state after being heated. A better LHP should have a lower start-up temperature. (3) Minimum start-up power, which refers to the minimum heat load required to start the heat pipe. A better LHP should have a smaller minimum start-up power. (4) Temperature fluctuation, during the startup process, the pressure and temperatures in the LHP will change violent, and on some situation the temperature will oscillate periodical. A better LHP should have smaller temperature fluctuation. Start-up performance of a LHP can be evaluated according to the above four characteristics.

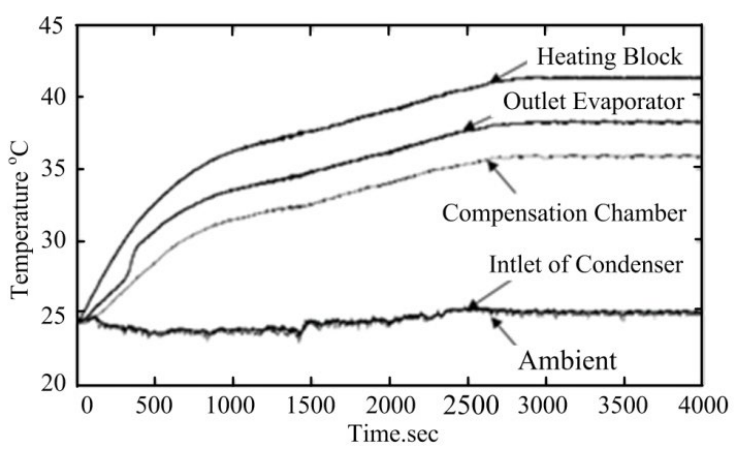

(a) $Q_{\text {in }}=5 \mathrm{~W}$

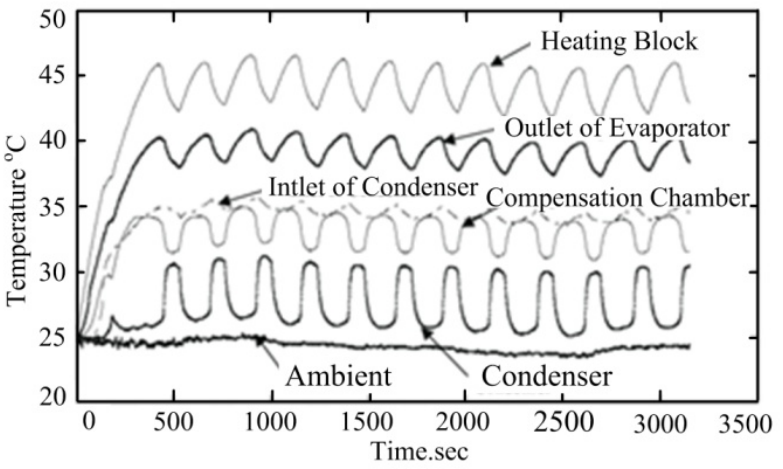

(b) $Q_{\text {in }}=20 \mathrm{~W}$

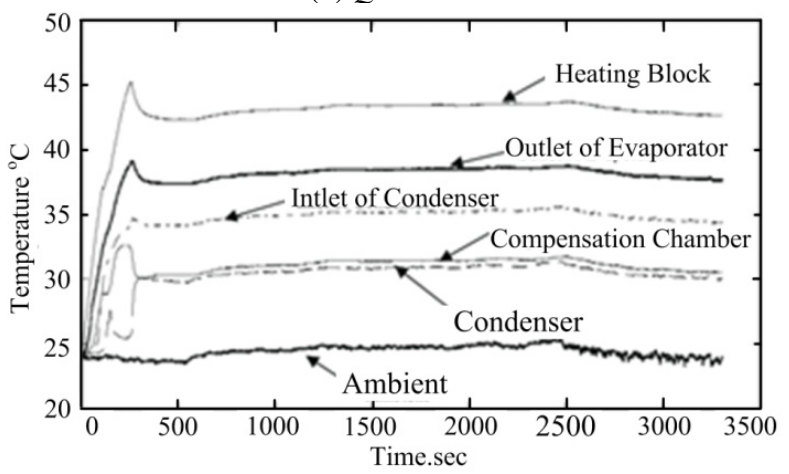

(c) $Q_{\text {in }}=30 \mathrm{~W}$

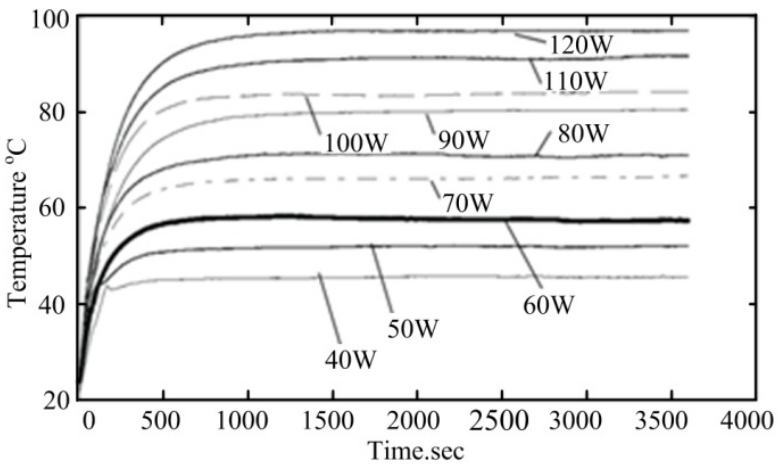

(d) $Q_{\text {in }}=40-120 \mathrm{~W}$

Fig. 5 Four different start-up modes, ((a) $Q_{\text {in }}=5 \mathrm{~W}$, (b) $Q_{\text {in }}=20 \mathrm{~W}$, (c) $Q_{\text {in }}=30 \mathrm{~W}$, (d) $Q_{\text {in }}=40-120 \mathrm{~W}$ ). (Huang et al. 2009). 
One of the advantages of the LHP is flexible start-up, which can be quickly started, stopped and restarted under certain conditions. Nevertheless, the study found that the loop heat pipe was not able to start successfully under any heat load. Huang et al. (2009) studied the startup process of heat pipes. It is found that the system dynamics of a LHP is a variable-structure system that changes with the operating conditions. The system dynamics in normal mode can be described by the secondorder transfer functions. It is also found that the start-up phenomena of a LHP can be classified into four modes: failure mode, oscillating mode, overshoot mode and normal mode based on the heat load (see Fig. 5). When the heat load is smaller than the minimum value $\left(Q_{\min }\right)$ such as 5 $\mathrm{W}$ in Fig. 5a, the evaporator temperature will continue to increase and cannot reach a steady state. The startup fails. When the $Q=20 \mathrm{~W}$ (see Fig. $5 \mathrm{~b}$ ), the start-up mode turn into oscillating mode, the vapor flow to the condenser is not stable but in oscillating or pulsating state. In this mode, the vapor flow is high enough to push the liquid segments existing in the connecting pipes and condenser forward. Since the vapor flow is not high enough due to low heat load, once the vapor flows to some distance, vapor condensation will create a retardation force to the flow. This results in the phenomenon of flow oscillation or pulsation as well as temperature oscillation observed in the condenser. As $Q=30 \mathrm{~W}$ (see Fig. $5 \mathrm{c}$ ), the vapor flow is higher than the oscillation mode and is able to push the liquid existing in the connecting pipes and condenser forward. A retardation force to the vapor flow is, however, generated at the beginning stage by liquid segments collision and merging with vapor condensation. The vapor pressure continues to rise with the heat load and finally reaches a critical value which is able to push the liquid to return to the evaporator to complete the fluid circulation along the loop. When $Q>30 \mathrm{~W}$ (see Fig. 5 d), a smooth startup is observed. Smooth transient curves which indicate a rise in the condenser temperature. This is supposed to be the normally operated mode of a LHP.

Wang et al. (2011) studied the relationship between start-up fluctuation and the thickness of the sintered capillary interlayer at low power, and explored the method to improve the start-up performance by changing the structure of the capillary wick. It was found that the fluctuation in the start-up process can be effectively suppressed by increasing the thickness of the capillary wicks. At the same time, after installing the cooling fins for the compensation chamber, the temperature of the compensation chamber can also be reduced to suppress the occurrence of the fluctuation, which provides a reference for the method of suppressing the fluctuation of the heat pipe during low power operation. Wang et al. (2014) and Wang et al. (2015) also found the relationship between start-up mode and power, and designed a doublesided heated evaporator to reduce the start-up fluctuation at low heat load, which can start successfully at 10W. Pastukhov et al. (2003) studied the effect of the initial vapor-liquid distribution in the evaporator /compensation chamber on the start-up characteristics of LHP. It was considered that the steam channel was filled with liquid before start-up. They found the existence of steam at the evaporation core was the most unfavorable start-up condition, while the steam channel had steam and the evaporation core was filled with liquid were the best start-up conditions. Cheung et al. (1998) first found the start-up threshold of LHP, pointing out that any heat load below this value will not allow LHP to start smoothly.

Some authors have tried to achieve stable start-up by modifying the structure of the evaporation chamber or adding auxiliary pumps, such as Zhu et al. (2016) used the ejector to remove the generated vapor in the compensation chamber, which could eliminate the need for the subcooling liquid supplied to the compensation chamber and improve the loop heat pipe performances (see Fig. 6a). Setyawan et al. (2018) designed a modified LHP that overcomes the dry-out problem by adding a diaphragm pump to accelerate fluid transportation (see Fig. 6b).Therefore, the fluid from the condenser can be drawn into the evaporator in two ways, namely, by simple capillary pumping or a combination of capillary pumping and diaphragm pumping. The results indicate that the installation of a diaphragm pump in a modified LHP system can prevent the occurrence of dry-out in the evaporator and achieve stable start-up.

However, the above-mentioned "ideas of improving the starting performance" have limitations in practical use. For example, reformation of the evaporation chamber structure increased manufacturing costs and the complexity of the structure, and limited the size of the space used. Therefore, how to improve the start-up performance of the LHP without increasing the complexity of the heat pipe structure should be the development direction.

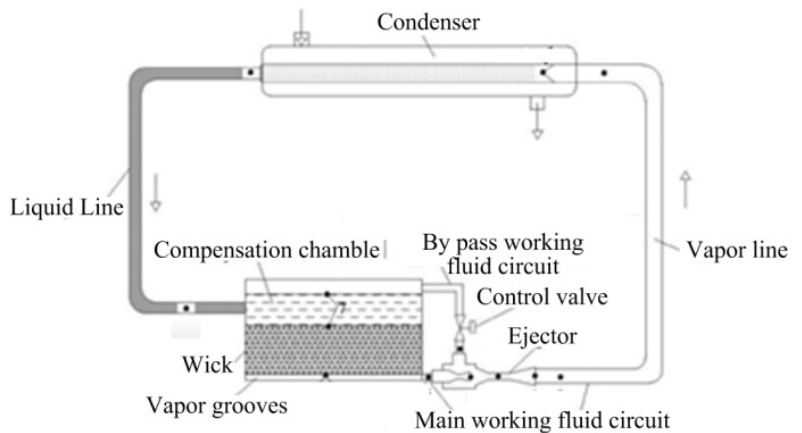

(a)

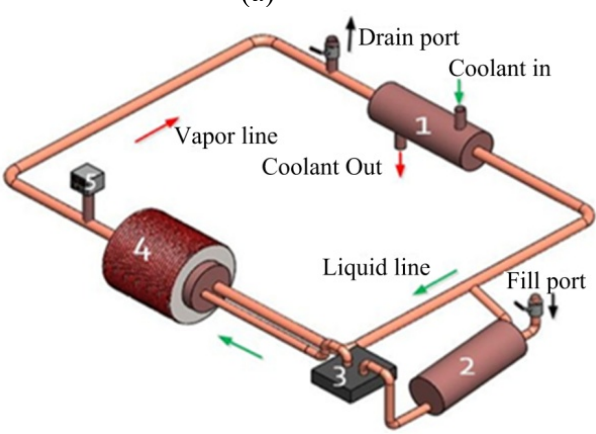

(b)

Fig. 6 Schematic diagram of LHP, (a) Adding ejector on LHP, ( Zhu et al. 2016), (b) Adding diaphragm pump on LHP (Setyawan et al. 2018).

\subsection{Anti-gravity Operation Capability of LHP}

The LHP was first applied at the aerospace field in the microgravity environment. The traditional view is that the performance of the LHP is not affected by the operating orientation. However, unlike the microgravity of space, when LHP is applied to the electronic equipment on the ground, gravity has a great influence on the distribution of the working fluid in the heat pipe, and the phase distribution of the working fluid mainly affects the heat transfer performance of the evaporator and condenser. Especially when the LHP works in the condition where the evaporator is higher than the condenser and compensation chamber, the gravity pressure difference will cause the increasing circulation resistance. At this point, the loop heat pipe often has problems such as over-temperature start-up, temperature fluctuations, which reduced the heat exchange capacity (Chen et al. 2006; Maydanik et al. 2015; Vershinin et al. 2007; Filippeschi et al. 2010; Chernysheva et al. 2015). Chernysheva et al. (2015) investigated the operating characteristics of a copper-water LHP to determine the effect of external factors such as the device orientation, in the range of heat loads from 20 to $600 \mathrm{~W}$ and at slopes from 0 to $60^{\circ}$ (see Fig. 7. From Fig. 7a to Fig. 7d, the heat sink temperature gradually increases from 20 to $80^{\circ} \mathrm{C}$ ).

They found that the slope dependence of the LHP heat transfer capacity decreases with increasing heat-sink temperature and practically disappears at a value of $80^{\circ} \mathrm{C}$. In this case the LHP thermal resistance decreases too and reaches a minimum value of $0.02 \mathrm{~K} / \mathrm{W}$ in the range of heat loads from 400 to $600 \mathrm{~W}$. They thought that the decrease in the maximal heat loads is the additional pressure losses caused by the 


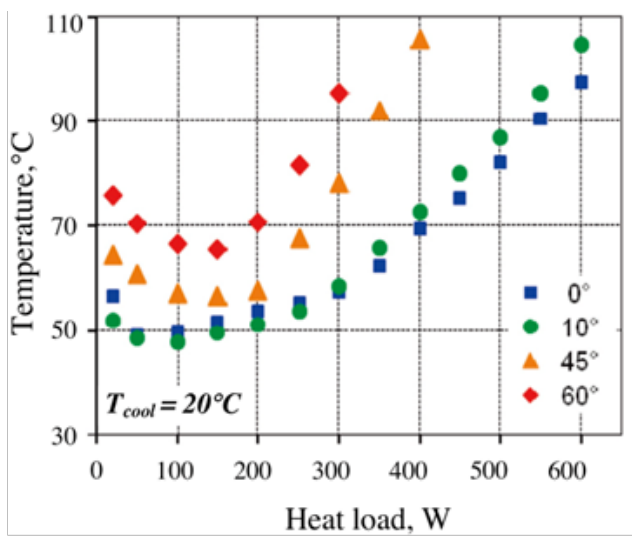

(a)

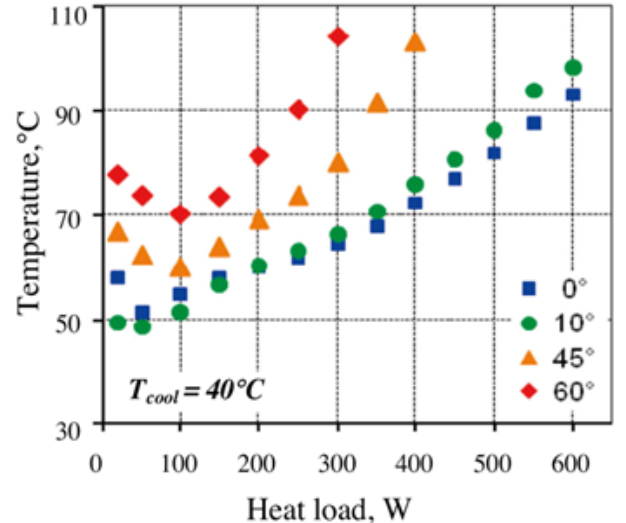

(b)

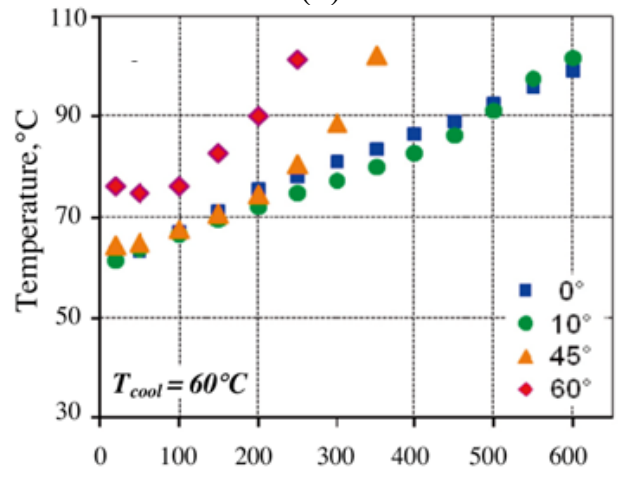

Heat load, W

(c)

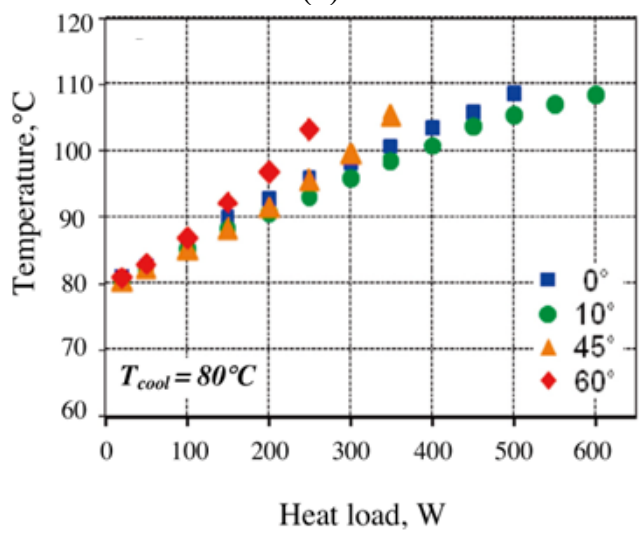

(d)

Fig. 7 Evaporator temperature of LHP at diffenrent angles and cooling temperatures. (a) $T_{\text {cool }}=20^{\circ} \mathrm{C}$, (b) $T_{\text {cool }}=40^{\circ} \mathrm{C}$, (c) $T_{\text {cool }}=60^{\circ} \mathrm{C}$, (d) $T_{\text {cool }}=80^{\circ} \mathrm{C}$, (Chernysheva et al. 2015). hydrostatic pressure. With the increase of LHP slope, the vapor needs larger pressure to push the liquid return from the condenser to the compensation chamber. So the saturation pressure and the saturation temperature increase, and the thermal resistance also rises.

Therefore, many scholars have analyzed the influence of the operation orientation and thermal resistance of the heat pipe and tried to put forward the solution. Celata et al. (2010) analyzed the operation of the heat pipe when the evaporator is above the condenser, and found that the heat pipe is difficult to start when the power is less than $20 \mathrm{~W}$. Odagiria et al. (2019) designed a flat rectangular evaporator for LHP to performed experimental investigation in six directions such as (1) evaporator under condenser, (2) wick above liquid core, (3) evaporator under compensation chamber, (4) evaporator above condenser, (5) wick under liquid core, and (6) evaporator above compensation chamber. When LHP was run at No. 4, it showed a higher temperature than No. 1 for all heat loads. This is caused by the larger gravity head for the case of No. 4 (see Fig. 8a). However, the lowest thermal resistance was 0.064 $\mathrm{K} / \mathrm{W}(Q=230 \mathrm{~W})$ for the No. 5 at high heat load (see Fig. $8 \mathrm{~b})$, which indicate that the LHP with wick above liquid core have the best heat transfer performance among six directions.

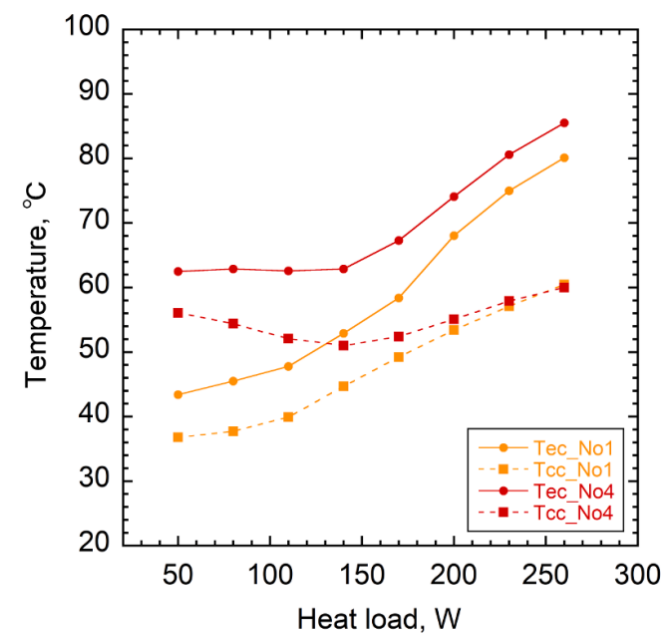

(a) Average temperature

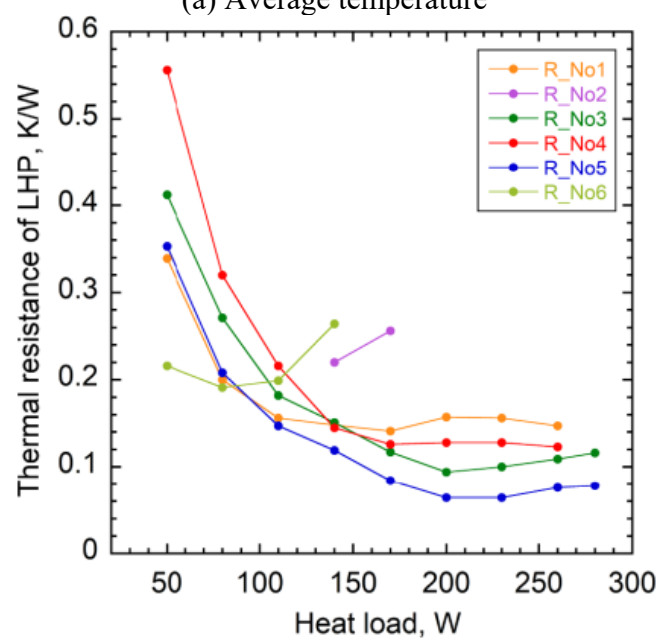

(b) Thermal resistance

Fig. 8 (a) Average temperature of the evaporator and the compensation chamber, (b) Thermal resistance of the LHP. (Odagiria et al. (2019).

For this phenomenon the author thought it is caused by the evaporator orientation and liquid-vapor distribution. In the case of No. 1, the evaporator is located in a vertical condition. Therefore, the upper part of the wick contacts with vapor phase while the bottom part of the wick is wet. It is considered that the evaporation occurs from the surface of 
the wick that contacts with the vapor phase. This phenomenon increases heat leakage from the evaporator to the $\mathrm{CC}$ in a large degree. Therefore, the operating temperature accordingly increases in the case of No. 1 . Based on the comparisons of the experimental results of six different orientations, it is clear that the evaporator orientation and location of liquid-vapor interface in the liquid core significantly affects the heat transfer performance.

Kaya et al. (2003) found that when the evaporator was higher than the compensation chamber, the operation temperature of LHP was higher; on the contrary, when the evaporator was lower than the compensation chamber, it was easy to fill the evaporation core with fluid, so the thermal leakage and operation temperature are both reduced. The literature (Gai et al. 2009) studied the operation characteristics of the micro loop heat pipe with flat evaporator to decide the effect of the tilt angle, the charging ratio and the heat load on the operation characteristics. The results showed that the evaporator temperature increased with the increasing heat load at a tilt angle of $50^{\circ}$ and the charging ratio of $50 \%$. At low heat loads, the steam generation rate in the evaporation section was slower, with longer start-up time. The start-up time of LHP with small charging ratio was shorter than that of LHP with large charging ratio, and the increasing tilt angle would reduce the evaporator temperature. At the same time, the tilt angle would affect the start-up time of the LHP, and the start-up time decreased with increasing tilt angle.

Obviously, a large number of studies have shown that heat transfer capacity of LHP was decreased under anti-gravity condition, and in many cases, over-temperature and temperature fluctuations will occur. In order to solve the above problems, some researchers have redesigned the heat pipe system. Deng et al. (2012) designed an anti-gravity heat pipe based on the bubble mode to strengthen the working fluid backflow. The results showed that the heat pipe can quickly reach a stable state within 20 minutes and can operate below $80^{\circ} \mathrm{C}$, when the power reached $80 \mathrm{~W}$. Tang et al. (2012) planned to increase the power of liquid backflow by sintering metal particles in the liquid line, but its operation temperature was still high, and the evaporator temperature was about $84^{\circ} \mathrm{C}$ at $90 \mathrm{~W}$. Some researchers have proposed a double compensation chamber structure (Bai et al. 2009; Lin et al. 2010): compensation chamber on both sides of the evaporator, which ensures that the LHP can be started smoothly in the most unfavorable operation direction, but the operation temperature varies with orientation. How to further promote the normal operation of LHP in the anti-gravity situation in the future remains to be further explored. In our opinion, strengthening the working fluid returning from the condenser to the compensation chamber and the evaporator is the first aspect to improve the anti-gravity operation capacity of the LHP. Therefore, on the theoretical research, the flow mechanism of working fluid in LHP should be studied. Enhance the capillary force of the porous wick and improve the wettability should be good methods. Also the Marangoni effect of the self-wetting fluid could regulate the backflow of the working fluid. On the other hand, if the space of the loop heat pipe allows, the circulation pump can be added to the pipeline which can ensures the evaporator have sufficient liquid supply under anti-gravity condition, and enhances critical heat flux. However, above practice will increase the manufacturing cost of the equipment and at the same time bring challenges to the sealing question of the LHP. Therefore, the LHP with high cost performance which can work under the anti-gravity condition needs to be developed and optimized.

\section{RESEARCH PROGRESS OF LHP WITH CAPILLARY WICK}

As an important part of the LHP, the porous wick is not only the main position where phase change occurs, but also absorbs the working fluid from the compensation chamber and supplies it to the evaporator for phase change. The capillary force and flow resistance of wicks directly affects the heat exchange capability of the LHP, and provides the cycle driving force of working fluid. And it is also the thermal barrier between the evaporator and the compensation chamber, which prevent heat leakage from the evaporator to the compensation chamber. So many scholars do lots of works to study the types of capillary wicks, wick materials, pore size, surface microstructure and wettability of wicks.

\subsection{Types and Materials of Porous Wick}

About capillary wick materials, scholars have done a lot of researches, such as wire mesh wicks, foam metal porous wicks and sintered metal wicks. Also they compared the effects of different type porous wicks on the heat transfer performance of LHP. Tharayi et al. (2016) designed a set of loop heat pipes with 7-layer 100 mesh wire mesh wick to investigate their heat transfer performance, using water as the working fluid. They found that LHP can operate stably under heating power of $20-380 \mathrm{~W}$ and its thermal resistance could be as low as $0.106 \mathrm{~K} / \mathrm{W}$. Zhou et al. (2016) studied a loop heat pipe with multi-layer metal foams as wick structure, using ethanol as the working fluid. They compared the properties of nickel metal foam and copper metal foam (see Fig. 9a), and analyzed the three stages during the start-up process. It can be seen from Fig.9 (a) that the nickel mental foam and copper metal foam has the similar structures, but the copper metal foam had a smaller pore size, and the porosity for them are $92.57 \%$ (copper foam) and $96.99 \%$ (nickel foam). Due to the higher thermal conductivity of copper foam, the LHP with copper foam wick has shorter start-up time and smaller thermal resistance compared with LHP with nickel foam wick.

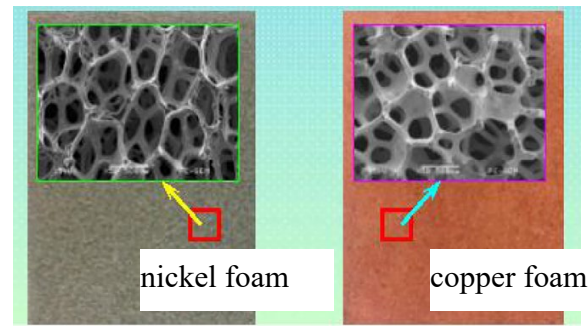

(a) Metal foam

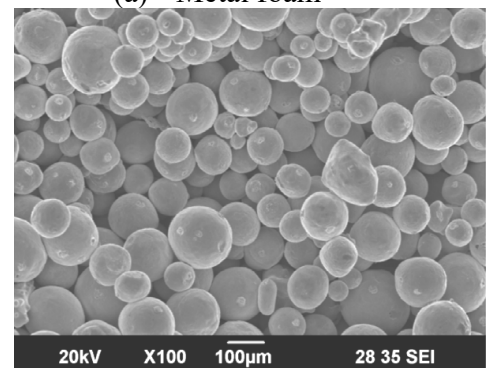

(b) Sintered copper powder

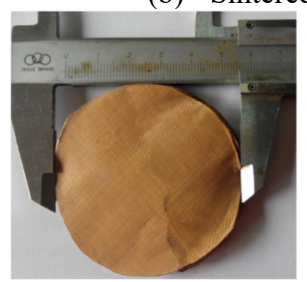

(c) metal mesh

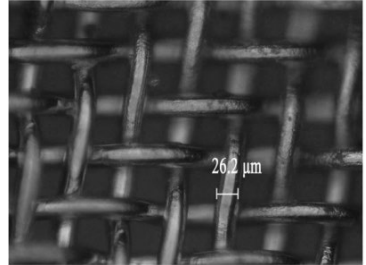

(d) Structure of mesh
Fig. 9 Appearance and SEM images: (a) nickel foam, copper foam. (Zhou et al. 2016), (b) Sintered copper powder (Xu et al. 2014), (c, d) metal mesh (Wang et al. 2016).

To study the comprehensive influence of the two kinds of wicks on the operation characteristics of LHP, it is necessary to compare the performance of the wicks under multiple working conditions. Wang et al. (2016) compared and analyzed the influence of wire mesh porous wick (see Fig. 9c and d) and sintered porous wick on the heat transfer performance of LHP. The aperture of sintered copper porous wick was 
in the range from 2.6 to $30 \mu \mathrm{m}$. In here the copper mesh wick is made of a 500 PPI (pores per inch) copper mesh with a copper thread of $26.2 \mu \mathrm{m}$, and the effective pore diameter distribution of the mesh wick was more uniform, about $35 \mu \mathrm{m}$. The porosity was calculated to be $66.5 \%$. It was found that the sintered porous wick was superior to the wire mesh porous wick in terms of minimum start-up power, start-up time and thermal resistance. Under the same power and tilt angle, the sintered porous wick started faster. So many scholars have increased the researches on the sintered porous wick (Xu et al. 2014; Li et al. 2012; Liu et al. 2012) (see Fig. 9b).

Because of the high thermal conductivity of copper, most of the wicks are made of copper powder. Sintered porous wick can control the pore diameter and other parameters of the capillary wick through the sintering process and particle selection. Based on people's understanding of sintering wick, Singh et al. (2009) conducted a systematic study on the effects of thermal conductivity, pore radius, and permeability of sintered porous wick. The heat performance of LHP with copper powder sintered wick and nickel powder sintered wick was tested in the experiment. It was found that the heat performance of LHP with copper wick was better than that of LHP with nickel wick, especially when the load was low. When the heating power was $80 \mathrm{~W}$ and the heat flux density was $21.33 \mathrm{~W} / \mathrm{cm}^{2}$, the evaporator temperature was about $95^{\circ} \mathrm{C}$.

To reduce the occurrence of heat leakage from evaporator to compensation chamber, Xin et al. (2018) proposed a composite LHP with different thermal conductivity wick, using nickel and copper. On the side close to the steam channel, the copper with high thermal conductivity was used to improve the heat conduction from the heat source to the capillary wick while the nickel powder with poor thermal conductivity was used at the compensation chamber to suppress heat leakage. Experiments showed that this design not only reduced the startup time but also reduced the operation temperature of LHP. Chen et al. (2012) tested the heat performance of LHP with the double-hole sintered nickel wick. When the heat flux density was $12.8 \mathrm{~W} / \mathrm{cm}^{2}$, the center temperature of the evaporator was lower than $60^{\circ} \mathrm{C}$, and the minimum thermal resistance was $0.33 \mathrm{~K} / \mathrm{W}$. Wu et al. (2013) produced a doublelayer capillary wick. The first layer was porous, providing channels for steam overflow and liquid suction. The second layer had uniform pore to suppress heat leakage. Compared with the traditional single-layer capillary wick, its maximum heat load was increased by $67 \%$ and the thermal resistance decreased by $100 \%$. The advantages and disadvantages of different types of wicks are summarized in Table 1.

\subsection{Effect of the Pore Size}

In the LHP, the evaporator is the main heat exchange places, where the working fluid change from liquid to gas and the condensed liquid enters the evaporator through the compensation chamber. So in the evaporator not only includes the phase change of working fluid, but also includes the two-phase flow of liquid and gas. As the most important part of evaporator, porous wick has a decisive influence on the above processes.

Table.1 Summary of different wicks

\begin{tabular}{|c|c|c|c|c|}
\hline Type & microstructure & materials & advantages & disadvantages \\
\hline $\begin{array}{l}\text { Groove wick } \\
\text { (Heng Tang et } \\
\text { al. 2018) }\end{array}$ & & $\begin{array}{l}\text { Aluminum, } \\
\text { stainless steel, } \\
\text { copper, etc. }\end{array}$ & $\begin{array}{lr}\text { Simple } & \text { structure and } \\
\text { easy } & \text { preparation } \\
\text { process. } & \end{array}$ & $\begin{array}{l}\text { Capillary force is small, } \\
\text { and surface treatment is } \\
\text { needed. }\end{array}$ \\
\hline $\begin{array}{l}\text { Sintered fiber } \\
\text { (Junyu Liu et } \\
\text { al. 2019) }\end{array}$ & & $\begin{array}{l}\text { Carbon fiber, } \\
\text { stainless steel } \\
\text { fiber, copper } \\
\text { fiber, etc. }\end{array}$ & $\begin{array}{l}\text { Good flexibility and } \\
\text { high strength. }\end{array}$ & $\begin{array}{l}\text { The wettability of } \\
\text { carbon fiber is } \\
\text { hydrophobic so it need } \\
\text { surface treatment. }\end{array}$ \\
\hline Mesh wick & & $\begin{array}{l}\text { stainless steel, } \\
\text { copper, etc. }\end{array}$ & $\begin{array}{l}\text { Low cost, high porosity } \\
\text { and simple structure. }\end{array}$ & $\begin{array}{l}\text { The pore size was } \\
\text { single. }\end{array}$ \\
\hline Metal foam & & $\begin{array}{l}\text { Nickel, stainless } \\
\text { steel, copper, } \\
\text { etc. }\end{array}$ & $\begin{array}{l}\text { Preparation technology } \\
\text { is relatively mature, } \\
\text { with high porosity, } \\
\text { large specific surface } \\
\text { area and low flow } \\
\text { resistance. }\end{array}$ & $\begin{array}{l}\text { The diameter of porous } \\
\text { wick is large, and the } \\
\text { capillary force is small. }\end{array}$ \\
\hline $\begin{array}{l}\text { Powder } \\
\text { sintering wick }\end{array}$ & & $\begin{array}{l}\text { Nickel, stainless } \\
\text { steel, copper, } \\
\text { etc. }\end{array}$ & $\begin{array}{l}\text { Preparation is simple } \\
\text { and thermal resistance } \\
\text { is small. Porosity can } \\
\text { be controlled by pore } \\
\text { forming agent. }\end{array}$ & $\begin{array}{l}\text { Pore structure is single } \\
\text { as without pore forming } \\
\text { agent, } \\
\text { manufacturing process } \\
\text { is relatively complex }\end{array}$ \\
\hline
\end{tabular}


During the operation of LHP, the liquid replenishment and steam overflow in capillary wick are affected by pore size, porosity, permeability and other parameters. The amount of steam released from a porous wick can be calculated using the Meléndez-Reyes formula (Meléndez et al. 2006):

$$
m_{\mathrm{v}}=\frac{\pi}{128}\left(\frac{\rho_{\mathrm{v}} \sigma}{\mu_{\mathrm{v}}}\right)\left(\frac{\varepsilon d_{\mathrm{ep}}{ }^{3}}{\delta}\right)
$$

where $m_{\mathrm{v}}$ is the steam mass flow, $\rho_{\mathrm{v}}, \sigma, \mu_{\mathrm{v}}$, and $\varepsilon$ are the steam density, surface tension, viscosity, and porosity, respectively. $\delta$ is the thickness of the capillary wick, and $d_{\mathrm{ep}}$ is the effective pore size. It can be seen from the formula (5) that a larger steam flow requires the capillary wick to have a larger $d_{\text {ep }}$ and porosity. However, according to the YoungLaplace equation (Yong et al. 1805),

$$
\Delta p=\frac{4 \sigma \cos \alpha}{d_{\mathrm{ep}}}
$$

wicks with small $d_{\mathrm{ep}}$ have large capillary force to improve the circulation force of the working fluid, which is conducive to the improvement of the thermal performance of the LHP. Boo et al. (2000) demonstrated that when the pore size was reduced from $25 \mu \mathrm{m}$ to 0.5

$\mu \mathrm{m}$, the maximum heat load was increased by $45 \%$. It can be seen from the above analyses that the effects of the effective pore size on the performance of the capillary wicks are more complex. Increasing $d_{\text {ep }}$ can strengthen the steam overflow, while decreasing $d_{\mathrm{ep}}$ can increase the capillary force of the wick and improve the circulation force of the

working fluid. At the same time, too small pore diameter would result in large resistance of vapor-liquid flow. Thus, there is an optimal pore aperture value for wicks in the LHP.

Studies have shown that the effective pore size of the wick is directly affected by the particle size (Semenic et al. 2008). Therefore, Li et al. (2015) used six copper powder particles with different particle sizes to produce the wicks and found that the heat transfer performance of the sintered wick changed significantly with the change of the copper powder particle size. They found that $75-100 \mu \mathrm{m}$ was the best particle size in single powder sintered capillary wick. Weibel et al. (2010) studied the relationship between thermal resistance and capillary wick thickness and particle size, and found that when the particle diameter was 45 $355 \mu \mathrm{m}$, there was a particle size with the maximum boiling heat transfer coefficient for a capillary wick with a fixed thickness. Xu et al. (2012) studied the relationship between the start-up performance and particle size of LHP and found that the start-up performance and heat transfer performance of LHP were the best when the particle diameter was 139 $\mu \mathrm{m}$. The LHP could start quickly in $150 \mathrm{~s}$ at a power of $30 \mathrm{~W}$. With an evaporator temperature of $60^{\circ} \mathrm{C}$, the maximum heat load could reach 500 W.

In recent years, researchers are increasingly finding that it is difficult to optimize the flow and heat transfer of a single-pore porous wick at high heat flux. So the key problem is to produce a kind of porous wick which can regulate gas-liquid two-phase flow, thus a two-pore distributed capillary wick was emerged at the historic moment. The dualpore distributed capillary wick formed by sintering metal powder can be mainly divided into bi-disperse and biporous wick. Fig. 10 shows scanning electron microscope images of a double-dispersed nickel capillary wick (Yeh et al. 2009) and biporous wick (Semenic et al. 2009). For the bidisperse wick, it can be made by sintering metal powder and pore-forming. After the sintering process was finished, removing the pore-forming, the bidisperse wick can be obtained (see Fig. 10a). Two sintering processes are required for biporous wick (see Fig. 10b), which make wick have both small and large pores. The small pore exists in the clusters and the large pores between the clusters.

The biggest difference between monoporous and biporous wick is that there are two distinct sizes in pore diameter. The small pore size is related to the size of the sintered pores between the powder particles and the large pore size is related to the channels between the clusters. Large pores which exist between two clusters increase the surface area for liquid film evaporation and decrease the flow resistance for the vapor venting to the downward microchannels. Small pores exist between particles, which create capillary force to supply liquid. Therefore, from the perspective of flow, two different sizes pores can solve the contradiction of capillary force and flow resistance. The small pores can provide large capillary pressure, while the large pores reduce flow resistance. From the perspective of heat transfer, the biporous wick can not only achieve small-pore liquid suction and large-pore vapor overflow, but large particle clusters can also increase the evaporation area of the thin liquid film.

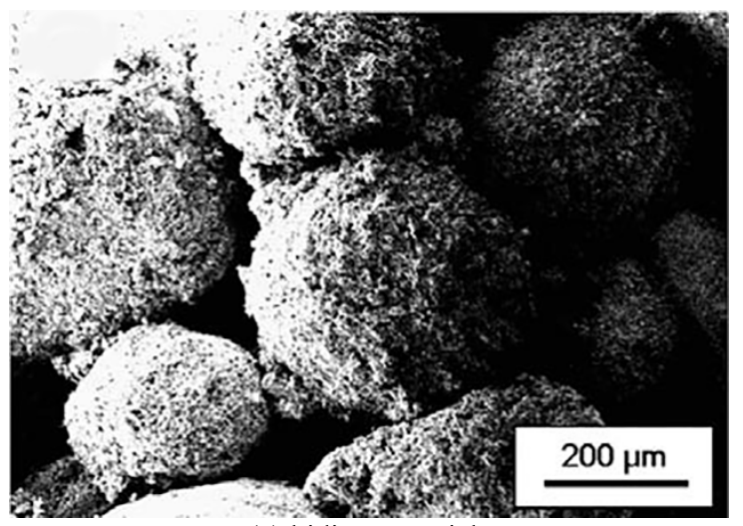

$$
\text { (a) bidisperse wick }
$$

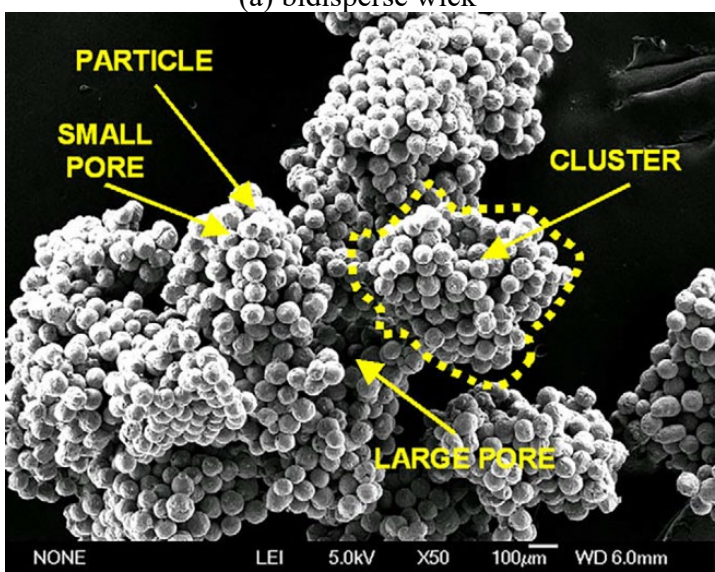

(b) biporous wick

Fig. 10 (a) SEM of bidisperse wick. (Yeh et al. 2009), (b) SEM of biporous wick. (Semenic et al. 2009).

There are many studies on the application of biporous wick in LHP, and they have proved the excellent performance. Lin et al. (2011) compared the effect of monoporous and biporous wick on the heat transfer performance of LHP, and found that biporous wick LHP has larger heat flux, lower thermal resistance and higher heat transfer coefficient. At $400 \mathrm{~W}$, the heat transfer coefficient of LHP with biporous wick is about 2.3 times that of LHP with monoporous wick. Their experiments also found that reducing the particle cluster size is more favorable for improving the heat transfer performance of LHP. Wu et al. (2015) experimentally investigated the use biporous wick with two pore sizes to enhance the performance of loop heat pipe (LHP). It is found that within a certain value range, increasing the content of the pore-forming agent and particle size of the pore-forming agent are conducive to the improvement of heat transfer performance for LHP, but exceeding the certain value will cause a reduction in capillary force, thereby causing a decrease in heat transfer performance. Therefore, found that 250-297 $\mu \mathrm{m}$ and $35 \mathrm{vol} \%$ was the optimal powder diameter and content, respectively. Under these parameters, the maximum heat load was $800 \mathrm{~W}$ and the thermal resistance was around $0.095 \mathrm{~K} / \mathrm{W}$. 
Actually the pore size of porous wick has complex relationships with porosity and the permeability which also influence the heat transfer of LHP. (Singh et al. 2009) found that on the same condensations, the increase of porosity helps to reduce the thermal conductivity, the increase of permeability will enhance the thermal performance of LHP. They also systematically studied the effects of thermal conductivity of sintered wick on the heat pipe performance. They found that the heat performance of LHP with sintered copper wick was better than that of LHP with sintered nickel wick, especially at low heat load. Ren et al. (2007) believed that permeability is determined by effective pore size and porosity. The effect of effective pore size and porosity can be reflected by permeability. Although there are complex relationships among pore size, permeability and porosity, it can be seen from the analysis that in the future researches, scholars should focus on the development of biporous and multi-scale porous wick for the function of regulating gasliquid two-phase flow.

\subsection{Effect of Wettability and Micro- nano Structured Surface}

With the development of micro-nano processing technology and new materials, domestic and foreign scholars have paid more attention to the influence of micro-nano modified surfaces on the boiling heat transfer, and realized that the heat transfer performance of LHP is not only limited by the pore size and permeability of capillary wicks, but also affected by the surface properties of capillary wicks. It is well known that the wettability and surface structure of heat transfer surfaces have important effects on the heat transfer coefficients. The relationships between the heat transfer and nucleation sites and superheat are as follows (Mikic et al. 1969):

$$
q=K \sqrt{\pi\left(k_{1} \sigma C_{\mathrm{p}}\right)} f D_{\mathrm{b}}{ }^{2} N_{\mathrm{a}} \Delta T_{\mathrm{w}}
$$

where $k_{1}$ is the thermal conductivity of liquid, $C_{\mathrm{P}}$ is the specific heat capacity, $K$ is a constant, $N_{\mathrm{a}}$ is the nucleation site density, $\Delta T_{\mathrm{w}}$ is the wall superheat. The results show that increasing nucleation site density and the frequency of bubble detachment on the boiling surface can enhance the heat transfer effectively. Numerous studies have shown that the density of nucleated cavities is related to surface microstructure, wettability and wall superheat.

To investigate the influence of the micro-nano structure on the heat transfer intensity, Lee et al. (2010) use anodizing technique to grow the well-ordered oxide nano-structures on the metal substrate. The pool boiling heat transfer coefficient and long-term performance of nanoporous surface were investigated with water. The experimental results show that the incipient wall superheat of pool boiling in nano-porous surface was lower than that in non-coating surface. The nucleate boiling heat transfer coefficient of nano-porous coating surface appeared higher than that of non-coating surface particularly at the low heat flux condition. Das et al. (2016) used vapor deposition coating approach to fabricate well-ordered of nanoparticle coated micro-nano-structures on metal surfaces. Fig. 11 showed that the boiling cures of silicon oxide coated surface move to the left, and the wall superheats are smaller at the same heat flux compared with the untreated surface. The thicker the thickness, the less superheat, the superheat can be reduced about $36 \%$ (see Fig. 11a). There is $58 \%$ enhancement in the heat transfer coefficient for silicon oxide coated surface over the untreated surface (see Fig. 11b).

This enhancement might be the reason of enhanced wettability, enhanced surface roughness and increased number of a small artificial cavity on a heating surface. Other similar studies also have found that the presence of micro-nano structures on the heat transfer surface reduces the initial boiling superheat and increases the heat transfer coefficient.

According to the research by Yang et al. (1988), increasing contact angle, that is, the hydrophobicity increases, the number of nucleated sites would increase gradually. However, in practice, most of LHP capillary wicks are metal materials, which are hydrophilic. According to Wenzel's

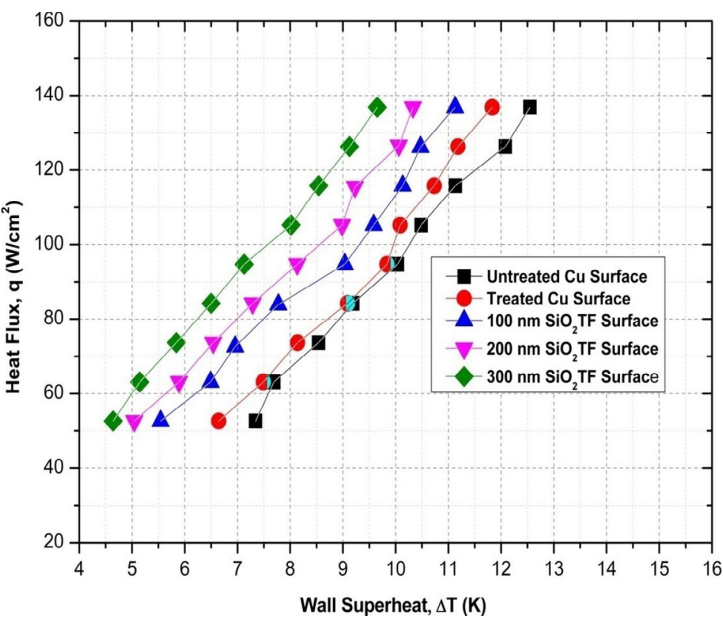

(a)

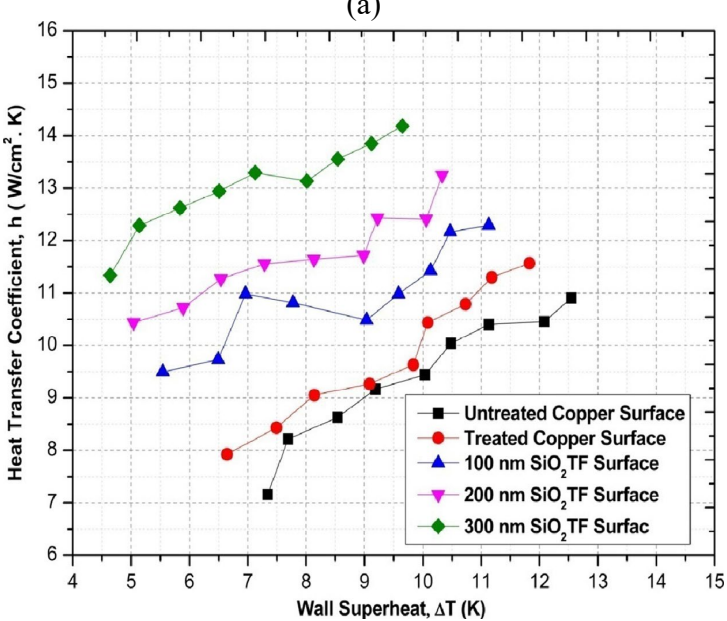

(b)

Fig. 11 (a) Variation of heat flux with wall superheat for five heating surfaces, (b) Dependency of heat transfer coefficient on heat flux for all heating surface. (Das et al. 2016).

equation, the surface hydrophilicity of capillary wicks can be increased with increasing roughness. The effect of surface wettability on bubble dynamics can be explained by the formula proposed by Fritz's equation (Fritz et al. 1935) for the relationship between bubble detachment diameter and contact angle:

$$
D_{\mathrm{b}}=0.0208 \alpha \sqrt{\frac{\sigma}{g\left(\rho_{1}-\rho_{\mathrm{v}}\right)}}
$$

It can be seen that the bubble detachment diameter decreases with the decreasing contact angle. According to Zuber (1963) formula for the frequency of bubble separation $\left(f_{b}\right)$ and the diameter of bubble separation $\left(D_{\mathrm{b}}\right)$ :

$$
f_{\mathrm{b}} D_{\mathrm{b}}=0.59\left[\frac{\sigma g\left(\rho_{1}-\rho_{\mathrm{v}}\right)}{\rho_{1}^{2}}\right]^{1 / 4}
$$

Obviously with increasing, the size of the bubbles generated on the boiling surface decreases, and the frequency increases. Therefore, the micro-nano structure on the surface increases the nucleation site density, while enhances hydrophilicity of surface, which affects the detachment diameter and frequency of bubbles. Generally speaking, the more bubbles and the higher bubble detachment frequency, the stronger boiling heat transfer and the better heat transfer performance. Li et al. (2008) investigated the nuclear boiling behavior on the surface with copper nanopillars and found that the existence of surface nanostructures can reduce the bubble detachment diameter and increase the detachment frequency. Similar phenomena were found in references (Kim et al. 2010; Chen et al. 2009). Dong et al. (2014) found that micro-nano 
structure surface prevents the formation of gas films, and thus increases the heat transfer coefficient and the critical heat flux. Lu et al. (2016) through visualization experimental found the surface with 3-D ordered nanoporous copper surface have significant enhancement in heat transfer coefficient and reduction in wall superheat compared with those of smooth surface and it can be attributed to the higher active nucleation site density and the improvement in hydrophilicity on nano porous surface

From above analysis, it can be found that the heat transfer performance of LHP can be improved by constructing micro-nano scale structures on the heat transfer surface or changing the surface wettability. To study the effect of micro-nano structure and wettability on the heat transfer performance of porous wick and LHPs, related scholars first study the capillary rise process in the porous wick, because the higher capillary raise height is the basic requirement of a good wick an essential quality of the high-quality porous wick. Li et al. (2018) fabricated a new multi-scale composite porous wick through sintering and $\mathrm{NaOH}$ treatment. The experimental results showed that through the corrosive of $\mathrm{NaoH}$ the contact angle of copper plate was reduced from $91.5^{\circ}$ to $22.2^{\circ}$ (see Fig. 12a and b), which indicates the surface hydrophilicity is improved. From the capillary pressure formula $\Delta P_{c}=2 \sigma \cos \theta / r$, where $\theta$ is the contact angle and $r$ is the effective pore radius, The decrease of effective pore size and the enhancement of hydrophilicity are beneficial to the increase of capillary force. The capillary force can be characterized by the rate-of-rise experiment based on the IR thermal image method. The results showed that nanostructures on the surface played a dominant role in forming the hydrophilic surface on the copper wick, which could achieve the higher capillary climbing height and rising velocity of working fluid for the wick. From Fig.12 (c) can find that the corrosive time has an important effect on the capillary climbing height. All the corrosive treated surfaces have higher capillary climbing height than the no corrosive treated surface. But the surface treated by $24 \mathrm{~h}$ corrosion has the highest climbing height value, and thus there exhibits an optimal corrosion time. In all, the nanostructures on the sintered copper powders surface can effectively enhance the capillary force.

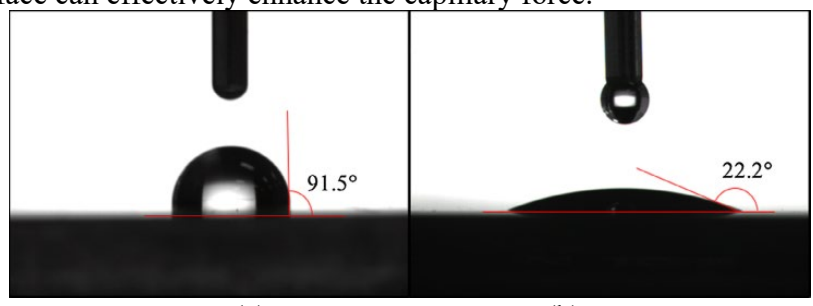

(a)
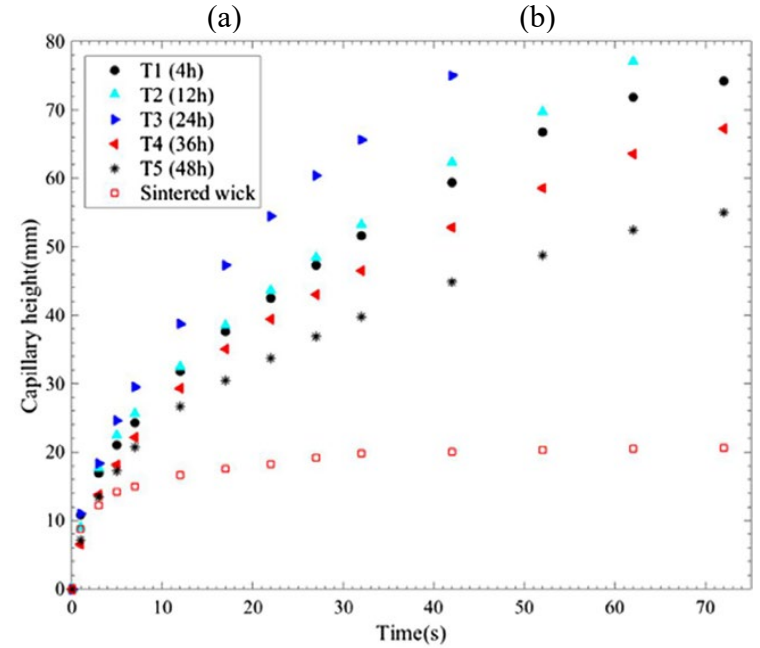

(c)

Fig. 12 Contact angle on (a) pure copper plate and (b) copper plate with nanostructure, (c) effect of corrosive time on the capillary rise processes of MCPW with water. (Li et al. 2018).
Particularly, the capillary limit of the wick generally depends on the following equation ( $\mathrm{Li}$ et al. 2011):

$$
Q=\frac{\rho_{1} A_{\mathrm{w}} h_{\mathrm{fg}}}{\mu_{1} l_{\mathrm{w}}}\left(\Delta P_{\mathrm{w}} K\right)
$$

where $Q$ is the heat flux, $\rho_{1}$ and $\mu_{1}$ are the density and dynamic viscosity of working fluid, $A_{\mathrm{w}}$ and $l_{\mathrm{w}}$ are the cross-sectional area and effective length of the wick, $h_{\mathrm{fg}}$ is the latent heat of vaporization, $\Delta P_{\mathrm{w}}$ is the pressure loss in the wick during liquid flow, and $K$ is the permeability. So the heat flux is proportional to the transformation area.

Similarity, Huang et al. (2017) use $\mathrm{NaoH}$ sculpture the grooved aluminum wicks, which significantly enhances the capillary performance of these wicks and increases the applicability of grooved aluminum heat pipes in space or in a horizontal direction. As shown in Fig. 13, the heat transfer limit $\left(Q_{\mathrm{c}, \max }\right)$ of the heat pipe is in proportion to the capillary performance parameter $\left(\Delta P_{\text {cap }} \cdot \mathrm{K}\right)$ of the grooved wick. The effect of corrosion parameters on $Q_{\mathrm{c}}$, max showed the same trend as the effect of corrosion parameters on $\Delta P_{\text {cap }} \cdot \mathrm{K}$. The calculated $Q_{\mathrm{c} \text {,max }}$ of the grooved aluminum wicks reached the maximum value of $9.00 \mathrm{~W} \pm 8.5 \%$ with the corrosion parameters of sample N1.25-10, far exceeding the value of $3.52 \mathrm{~W} \pm 1.5 \%$ for the non-corroded wicks, being improved approximately $155 \%$ compared to the one without corrosion.

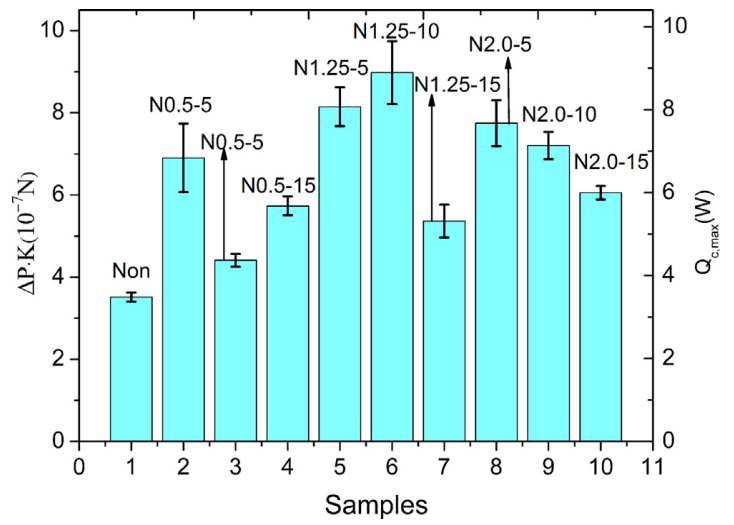

Fig. 13 Effect of concentration and time of corrosion on the capillary performance parameter $\left(\Delta \mathrm{P}_{\text {cap }} \cdot \mathrm{K}\right)$ and corresponding capillary limit $\left(Q_{\mathrm{c}}\right.$, $\max$ ). (Huang et al. 2017).

To further improve the heat performance of heat pipe, Tang et al. (2018) fabricated the v-shaped groove wick made by the ploughingextrusion method. The capillary structure was characterized by the climbing test of acetone in capillary tube, and the liquid rising process was monitored by infrared imaging technology. The experimental results showed that the contact angle of aluminum surface was decreased from $75^{\circ}$ to $15^{\circ}$, and the hydrophilicity was enhanced greatly. The capillary rise height of corroded aluminum wick is obviously higher than that of uncorroded wick. Other scholars such as Lu et al. (2017); Tang et al. (2017) and Yang et al. (2017) constructed the surface nanostructures on the groove or fiber wicks to improve the capillary performance. At the same time, the applications of wick with micro-nano structure in heat pipe were also reported. For example, laser etching technique was used to etch the surface of the evaporator to form a micro-nano structure surface (Wang et al. 2018) (see Fig. 14a). The results of thermal experiments show that the maximum heat flux density is $1.5-3.5$ times that of traditional methanol LHP. When the power is $140 \mathrm{~W}$, the heat transfer coefficient can reach $42.17 \mathrm{~kW} /\left(\mathrm{m}^{2} \mathrm{~K}\right)$, the maximum heat flux is $35.12 \mathrm{~W} / \mathrm{cm}^{2}$, and evaporator bottom plate temperature is less than $70^{\circ} \mathrm{C}$ (see Fig. $14 \mathrm{~b}$ and c).

Recently, Yang et al. (2015) applied multi-scale copper wire Mesh structure to fabricate flexible heat pipes, this multi-scale wick has superhydrophilicity, which can greatly improve liquid transportation capability, under the optimal operating conditions the thermal resistance of the heat pipe can be reduced to $0.01 \mathrm{~K} / \mathrm{W}$. Liu et al. (2019) reported on the working characteristics of a flat plate LHP with a thin 


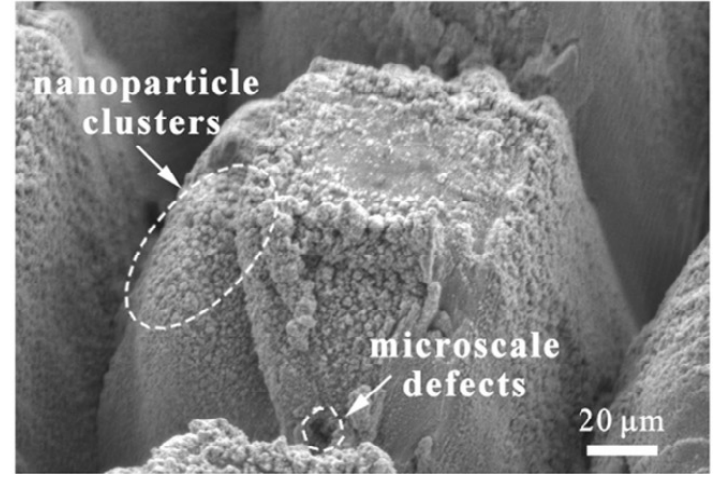

(a) SEM images

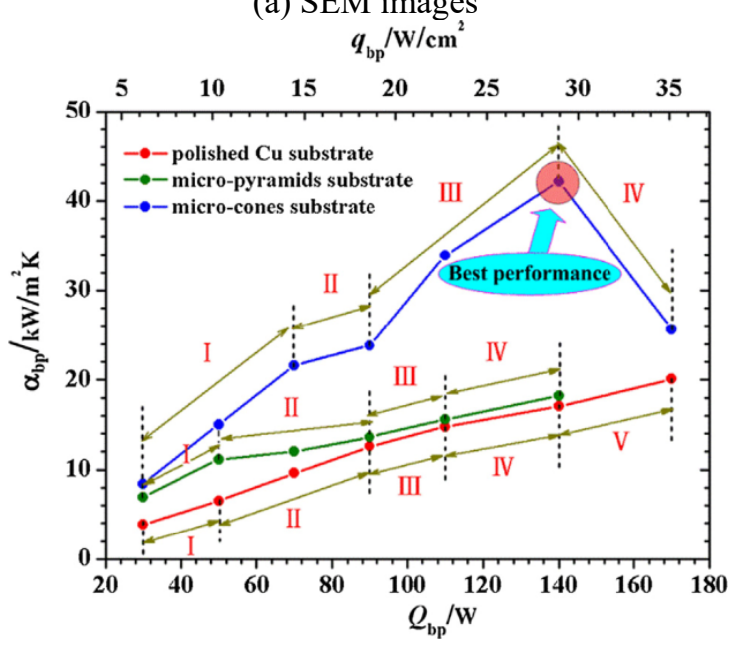

(b) Boiling pool heat transfer coefficient $q_{\mathrm{bp}} / \mathrm{W} / \mathrm{cm}^{2}$

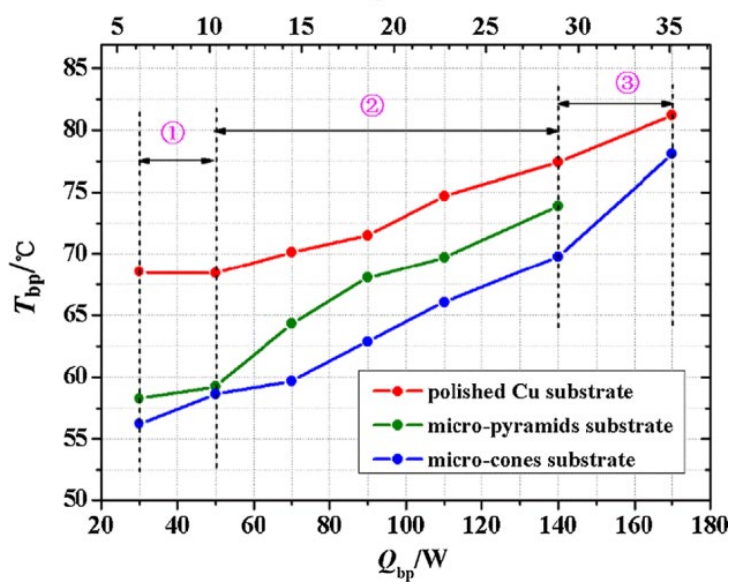

(c)Steady-state temperature

Fig. 14 (a) SEM images, (b) boiling pool heat transfer coefficient variations with the heat loads, (c) steady-state temperature variations of the $T_{\mathrm{bp}}$ for different substrates. (Wang et al. 2018).

polyacrylonitrile-based carbon fiber as a porous wick. The results showed that the capillary wick had hydrophilic property after copper plating. The LHP with modified thin carbon fiber as capillary wick can start up successfully and keep stable operation in the range of $15-75 \mathrm{~W}\left(12 \mathrm{~W} / \mathrm{cm}^{2}\right)$. The above researches have brought good enlightenment and laid a good foundation for further improving the heat transfer performance of LHP.

\section{CONCLUSIONS AND PROSPECTS}

This paper introduced the working principle, the mechanism of thermal cycle and the advantages of loop heat pipe compared with other heat pipes, and summarized the development status of loop heat pipe in the aspects of wick structure, start-up performance, temperature fluctuation, anti-gravity operation and effects of various physical parameters on the heat transfer performance.

(1) Seen from the operation characteristics, the loop heat pipe belongs to the heat pipe with vapor-liquid phase separation, indicating relatively different from other heat pipes. It overcomes the requirements and limitations of the field position, and can arbitrarily arrange the gas and liquid pipe line according to the space situation. It possesses advantages of high heat transfer efficiency and small internal thermal resistance, increasing the application ranges and providing an ideal solution to dissipate the high amount of heat flux generated in the electronics systems.

(2) Start-up performance, temperature fluctuations, anti-gravity operation capability and evaporator temperature are important indexes to evaluate the heat transfer performance of the loop heat pipe. How to improve the heat transfer performance of the loop heat pipe is the goal of many researchers. They studied the influence of various parameters on the operational characteristics of LHPs, such as structure types, inclination angle, work environment, surface structure and wettability of wicks inside the loop heat pipe. In terms of start-up performance, it is mainly to reduce start-up time, startup temperature and minimum start-up power, and suppress temperature fluctuation during start-up process. In terms of heat pipe operation, it is mainly to reduce the operating temperature of evaporator as much as possible and ensure the operation stability with small temperature fluctuation. The excellent loop heat pipe needs to run under the high heat flux or the state of anti-gravity situation overcoming the influence of gravity. Therefore, future research should focus on how to improve the start-up performance, heat transfer coefficient and anti-gravity operation capacity, such as using the gradient porous wick structure and self-wetting fluid, even use sintered porous wicks with nanofluids.

(3) Among all the physical parameters, the pore size, wettability and micro-nano structure of wick are the most important ones to affect the loop heat pipe. Therefore, a lot of research work is mainly reflected in these three aspects. Some scholars proposed the concept of biporous wick which is beneficial to realize the function of vaporliquid separation in the phase change heat transfer compared with monoporous wick, large pores for vapor overflow and small pores for liquid suction. Furthermore, the method of building micro-nano structures and changing wattability on the porous wick surface was proposed to enhance heat transfer performance from increasing surface area and liquid supply aspects. However, the visualization in the evaporator with micro-nano structure on the wick surface and the stability of long-term operation has not been systematically studied. Performing visual analysis in the evaporator of LHP is an important research topic in the future, especially for studying the internal phase change patterns and processes.

\section{ACKNOWLEDGEMENTS}

This work is supported by the Natural Science Foundation of China (51676071), and the Key Project of Natural Science Foundation of China (51436004). 


\section{REFERENCES}

Abdoli, A., Jimenez, G., and Dulikravich, G., 2015 "Thermo-fluid analysis of micro pin-fin array cooling configurations for high heat fluxes with a hot spot," International Journal of Thermal Sciences, 90, 290-297.

https://doi.org/10.1016/i.ijthermalsci.2014.12.021.

Ambirajan, A., Adoni, A.A., Vaidya, J.S., Rajendran, A.A., Kumar, D., and Dutta, P., 2012, "Loop Heat Pipes: A Review of Fundamentals, Operation, and Design," Heat Transfer Engineering, 33, 387-405. https://doi.org/10.1080/01457632.2012.614148.

An, Y.S., and Zhang, Y.F., 2013, "The Experimental Research on the Reduction of Heat Loss Rate of Wellbores with two-Phase Closed Thermosyphon Wellbore," Research Journal of Applied Sciences, Engineering and Technology, 5, 5154-5158.

https://doi.org/10.19026/rjaset.5.4258.

Aung, N.Z., and Li, S., 2013, "Numerical investigation on effect of riser diameter and inclination on system parameters in a two-phase closed loop thermosyphon solar water heater," Energy Conversion and Management, 75, 25-35.

https://doi.org/10.1016/j.enconman.2013.06.001.

Bai, L.Z., Lin, G.P., Zhang, H.X., and Wen, D.S., 2009, "Mathematical modeling of steady-state operation of a loop heat pipe," Applied Thermal Engineering, 29, 2643-2654.

https://doi.org/10.1016/j.applthermaleng.2008.12.040.

Bai, L.Z., Lin, G.P., Wen, D.S., and Feng, J.T., 2009, "Experimental investigation of start-up behaviors of a dual compensation chamber loop heat pipe with insufficient fluid inventory," Applied Thermal Engineering, 29, 1447-1456.

https://doi.org/10.1016/j.applthermaleng.2008.06.019.

Becker, S., Vershinin, S., Sartre, V., Laurien, E., Bonjour, J., and Maydanik, Y.F., 2011, "Steady state operation of a copper-water LHP with a flat-oval evaporator," Applied Thermal Engineering, 31, 686-695. https://doi.org/10.1016/j.applthermaleng.2010.02.005.

Belhardj, S., Mimouni, S., Saidane, A., and Benzohra, M., 2003, "Using micro-channels to cool microprocessors: a transmission-line-matrix study," Microelectronics Journal, 34 247-253.

https://doi.org/10.1016/s0026-2692(03)00004-1

Boo, J.H., 2000, "Effects of mesh size in a flat evaporator and condenser cooling capacity on the thermal performance of a capillary pumped loop," Ksme International Journal, 14, 121-129.

https://doi.org/10.1007/BF03184778

Brenton S.T., and Kevin W.I., 2019, "Asets-Ii Oscillating Heat Pipe Space Flight Experiment: The First Six Months On Orbit," Frontiers in Heat and Mass Transfer, 10, 24.

https://doi.org/10.5098/hmt.12.24.

Celata, G.P., Cumo, M., and Furrer M., 2010, "Experimental tests of a stainless steel loop heat pipe with flat evaporator," Experimental Thermal and Fluid Science, 34, 866-878.

https://doi.org/10.1016/j.expthermflusci.2010.02.001.

Chen, B.B., Liu, W., Liu, Z.C., Li, H., and Yang, J.G., 2012, "Experimental investigation of loop heat pipe with flat evaporator using biporous wick," Applied Thermal Engineering, 42, 34-40.

https://doi.org/10.1016/j.applthermaleng.2012.03.006

Chen, Y., Groll, M., Mertz, R., Maydanik, Y.F., and Vershinin, S.V., 2006, "Steady-state and transient performance of a miniature loop heat pipe," International Journal of Thermal Sciences, 45, 1084-1090. https://doi.org/10.1016/j.ijthermalsci.2006.02.003.

Chen, Y., Mo, D.C., Zhao, H.B., Ding, N., and Lu, S.S., 2009,"Pool boiling on the superhydrophilic surface with TiO2 nanotube arrays," Science in China Series E: Technological Sciences, 52, 1596-1600. https://doi.org/CNKI:SUN:JEXG.0.2009-06-015

Chernysheva, M.A., Yushakova, S.I., and Maydanik, Y.F., 2015, "Effect of external factors on the operating characteristics of a copper-water loop heat pipe," International Journal of Heat and Mass Transfer, 81, 297304.

https://doi.org/10.1016/j.ijheatmasstransfer.2014.10.037.

Cheung, K.H., Hoang, T.T., Ku, J., and Kaya, T., 1998, "Thermal Performance and Operational Characteristics of Loop Heat Pipe (NRL LHP)," 28th International Conference on Environmental Systems Danvers, Massachusetts July.

Cotter, T.P., 1965, "Theory of heat pipes," Los Alamos Scientific Lab: Report No. LA-3246-MS.

Das, S., Kumar, D.S., and Bhaumik, S., 2016, "Experimental study of nucleate pool boiling heat transfer of water on silicon oxide nanoparticle coated copper heating surface," Applied Thermal Engineering, 96, 555567.

https://doi.org/10.1016/j.applthermaleng.2015.11.117

Deng, W., Xie, Z., Tang, Y., and Zhou, R., 2012, "Experimental investigation on anti-gravity loop heat pipe based on bubbling mode," Experimental Thermal and Fluid Science, 41, 4-11.

https://doi.org/10.1016/j.expthermflusci.2012.01.030

Dong, L.N., Quan, X.J., and Cheng, P., 2014, "An experimental investigation of enhanced pool boiling heat transfer from surfaces with micro/nano-structures," International Journal of Heat and Mass Transfer, 71, 189-196.

https://doi.org/10.1016/j.ijheatmasstransfer.2013.11.068

Faghri, A., 2012 "Review and Advances in Heat Pipe Science and Technology," Journal of Heat Transfer, 134, 123001. https://doi.org/10.1115/1.4007407.

Filippeschi, S., 2011, "Comparison between miniature periodic twophase thermosyphons and miniature LHP applied to electronic cooling equipment," Applied Thermal Engineering, 31, 795-802. https://doi.org/10.1016/j.applthermaleng.2010.10.028.

Fritz, W., 1935,"Berechnung des Maximalvolumens von Dampfblasen," Phys. Z. 36, 379-384.

Gai, D.X., Liu, Z.C., Liu, W., and Yang, J., 2009, "Operational characteristics of miniature loop heat pipe with flat evaporator," Heat and Mass Transfer, 46, 267-275.

https://doi.org/10.1007/s00231-009-0563-0

Gaugler, R. S. 1944, "Heat transfer device," 12.

Grover, G.M., Cotter, T.P. and Erikson, G.F., 1964 "Structure of very high thermal conductance," Journal of Applied Physics, 35.

Huang, B., Huang, H., and Liang, T., 2009, "System dynamics model and start-up behavior of loop heat pipe," Applied Thermal Engineering, 29, 2999-3005.

https://doi.org/10.1016/j.applthermaleng.2009.03.015.

Huang, G.H., Yuan, W., Tang, Y., Zhang, B., Zhang, S.W., and Lu, L.S., 2017, "Enhanced capillary performance in axially grooved aluminium wicks by alkaline corrosion treatment," Experimental Thermal and Fluid Science, 82, 212-221.

https://doi.org/10.1016/j.expthermflusci.2016.11.020 
Hussein, H.M.S., 2003, "Optimization of a natural circulation two phase closed thermosyphon flat plate solar water heater," Energy Conversion and Management, 44, 2341-2352.

https://doi.org/10.1016/S0196-8904(02)00255-8.

Ji, X.B., Wang, Y., Xu, J.L., and Huang, Y.P., 2017, “Experimental study of heat transfer and start-up of loop heat pipe with multiscale porous wicks," Applied Thermal Engineering, 117, 782-798.

https://doi.org/10.1016/j.applthermaleng.2017.01.084.

Jouhara, H., Anastasov, V., and Khamis, I., 2009, "Potential of heat pipe technology in nuclear seawater desalination," Desalination, 249, 1055 1061.

https://doi.org/10.1016/j.desal.2009.05.019.

Kaya, T., and Ku, J., 2003, "Thermal Operational Characteristics of a Small-Loop Heat Pipe," Journal of Thermophysics and Heat Transfer, 17, 464-470.

https://doi.org/10.2514/2.6805

Kim, S., Kim, H.D., Kim, H., Ahn, H.S., Jo, H., Kim, J., and Kim, M.H., 2010, "Effects of nano-fluid and surfaces with nano structure on the increase of CHF," Experimental Thermal and Fluid Science, 34(4), 487495.

https://doi.org/10.1016/j.expthermflusci.2009.05.006

Krishna, J., Kishore, P.S., and Solomon, A.B., 2017, "Heat pipe with nano enhanced-PCM for electronic cooling application," Experimental Thermal and Fluid Science, 81, 84-92.

https://doi.org/10.1016/j.expthermflusci.2016.10.014.

Ku, J., 1999, "Operating Characteristics of Loop Heat Pipes," $29^{\text {th }}$ International Conference on Environmental System.

Launay, S., Sartre, V., and Bonjour, J.. 2007, "Parametric analysis of loop heat pipe operation: a literature review," International Journal of Thermal Sciences, 46, 621-636.

https://doi.org/10.1016/j.ijthermalsci.2006.11.007.

Lee, C.Y., Hossain Bhuiya, M.M., and Kim, K.J., 2010, "Pool boiling heat transfer with nano-porous surface," International Journal of Heat and Mass Transfer, 53, 4274-4279.

https://doi.org/10.1016/j.ijheatmasstransfer.2010.05.054

Li, C., Wang, Z.K., Wang, P.I., Peles, Y., Koratkar, N., and Peterson, G.P., 2008, "Nanostructured copper interfaces for enhanced boiling," Small, 4(8), 1084-1088.

Https://doi.org/10.1002/smll.200700991

Li, H., Fu, S.J., Li, G.F., Fu, T., Zhou, R., Tang, Y., Tang, B., Deng, Y., and Zhou, G.F., 2018, "Effect of fabrication parameters on capillary pumping performance of multi-scale composite porous wicks for loop heat pipe," Applied Thermal Engineering, 143, 621-629.

https://doi.org/10.1016/j.applthermaleng.2018.07.143

Li, H., Liu, Z.C., Chen, B.B., Liu, W., Li, C., and Yang, J.G., 2012, "Development of biporous wicks for flat-plate loop heat pipe," Experimental Thermal and Fluid Science, 37, 91-97. https://doi.org/10.1016/j.expthermflusci.2011.10.007

Li, H., Wang, X.G., Liu, Z.S., Tang, Y., Yuan, W., Zhou, R., and Li, Y.J., 2015, "Experimental investigation on the sintered wick of the antigravity loop-shaped heat pipe," Experimental Thermal and Fluid Science, 68, 689-696.

https://doi.org/10.1016/j.expthermflusci.2015.06.020

Li, J., and Peterson, G.P., 2011, "3D heat transfer analysis in a loop heat pipe evaporator with a fully saturated wick," International Journal of Heat and Mass Transfer, 54, 564-574. https://doi.org/10.1016/j.ijheatmasstransfer.2010.09.014

Li, Z.W., Lv, L.C., and Li, J., 2016, "Combination of heat storage and thermal spreading for high power portable electronics cooling," International Journal of Heat and Mass Transfer, 98, 550-557. https://doi.org/10.1016/j.ijheatmasstransfer.2016.03.068.

Lin, F.C., Liu, B.H., Juan, C.C., and Chen, Y.M., 2011, "Effect of pore size distribution in bidisperse wick on heat transfer in a loop heat pipe," Heat and Mass Transfer, 47, 933-940. https://doi.org/10.1007/s00231-011-0841-5

Lin, G.P., Li, N., Bai, L.Z., and Wen, D.S., 2010, "Experimental investigation of a dual compensation chamber loop heat pipe," International Journal of Heat and Mass Transfer, 53, 3231-3240. https://doi.org/10.1016/j.ijheatmasstransfer.2010.03.003

Liu, J.Y., Zhang, Y.X., Feng, C., Liu, L.F., and Luan, T., 2019, "Study of copper chemical-plating modified polyacrylonitrile-based carbon fiber wick applied to compact loop heat pipe," Experimental Thermal and Fluid Science, 100, 104-113.

https://doi.org/10.1016/j.expthermflusci.2018.07.008

Liu, Z.C., Li, H., Chen, B.B., Yang, J.G., and Liu, W., 2012, "Operational characteristics of flat type loop heat pipe with biporous wick," International Journal of Thermal Sciences, 58, 180-185.

https://doi.org/10.1016/j.ijthermalsci.2012.02.027

Lu, L.S., Fu, T., Tang, Y., Tang, T., Tang, B., and Wan, Z.P., 2016, “A novel in-situ nanostructure forming route and its application in poolboiling enhancement," Experimental Thermal and Fluid Science, 72, 140-148.

https://doi.org/10.1016/j.expthermflusci.2015.11.005

Lu, L.S., Sun, J.W., Liu, Q.P., Liu, X.K., and Tang, Y., 2017, “Influence of electrochemical deposition parameters on capillary performance of a rectangular grooved wick with a porous layer," International Journal of Heat and Mass Transfer, 109, 737-745.

https://doi.org/10.1016/j.ijheatmasstransfer.2017.02.054

Maydanik, Y., Vershinin, S., Chernysheva, M., and Yushakova, S., 2011, "Investigation of a compact copper-water loop heap pipe with a flat evaporator," Applied Thermal Engineering, 31, 3533-3541.

https://doi.org/10.1016/j.applthermaleng.2011.07.008.

Maydanik, Y.F., 2005, “Loop heat pipes,” Applied Thermal Engineering, 25, 635-657.

https://doi.org/10.1016/j.applthermaleng.2004.07.010.

Maydanik, Y.F., Pastukhov, V.G., and Chernysheva, M.A. 2015, "Development and Investigation of a Miniature Copper-Acetone Loop Heat Pipe with a Flat Evaporator," Journal of Electronics Cooling and Thermal Control, 05, 77-88. https://doi.org/10.4236/jectc.2015.54006.

Meléndez, E., and Reyes, R., 2006, "The pool boiling heat transfer enhancement from experiments with binary mixtures and porous heating covers," Experimental Thermal and Fluid Science, 30, 185-192. https://doi.org/10.1016/j.expthermflusci.2005.05.005

Mikic, B.B., and Rohsenow, W.M., 1969, "A new correlation of poolboiling data including the effect of heating surface characteristics," International Journal of Heat and Mass Transfer, 91, 245-250. https://doi.org/10.1115/1.3580136

Mirmanto I.B., Alit I.M.A., and Sayoga R., 2018 "Experimental Cooler Box Performance Using Two Different Heat Removal Units: A Heat Sink Fin-Fan, And A Double Fan Heat Pipe," Frontiers in Heat and Mass Transfer, 10,34. 


\section{https://doi.org/10.5098/hmt.10.34.}

Nada,S.A., Ghetany, H.H., and Hussein, H.M.S., 2004, "Performance of a two-phase closed thermosyphon solar collector with a shell and tube heat exchanger," Applied Thermal Engineering, 24, 1959-1968. https://doi.org/10.1016/j.applthermaleng.2003.12.015.

Odagiria, K., and Nagano, H., 2019, "Heat transfer characteristics of flat evaporator loop heat pipe under high heat flux condition with different orientations," Applied Thermal Engineering, 153, 823-836. https://doi.org/10.1016/j.applthermaleng.2019.02.022

Pastukhov, V.G., Maidanik, Y.F., Vershinin, C.V., and Korukov, M.A.. 2003, "Miniature loop heat pipes for electronics cooling," Applied Thermal Engineering, 23, 1125-1135. https://doi.org/10.1016/s1359-4311(03)00046-2.

Popova, N., Schaeffer, C., and Avenas, Y., 2006, "Fabrication and experimental investigation of innovative sintered very thin copper heat," $37^{\text {th }}$ IEEE Power Electronics Specialists Conference..

Ren C., Wu Q.S., and Hu M.B.. 2007 "Heat Transfer in Loop Heat Pipel"s Wick: Effect of Porous Structure Parameters," Journal of Thermophysics and Heat Transfer, 21(4). 702-711.

https://arc.aiaa.org/doi/abs/10.2514/1.28122

Semenic, T., and Catton, I., 2009, "Experimental study of biporous wicks for high heat flux applications," International Journal of Heat and Mass Transfer, 52, 5113-5121. https://doi.org/10.1016/j.ijheatmasstransfer.2009.05.005

Semenic, T., Lin, Y.Y., and Catton, I., 2008, "Thermophysical Properties of Biporous Heat Pipe Evaporators," Journal of Heat Transfer, 130, 334334.

https://doi.org/10.1115/1.2790020

Setyawan, I., Putra, N., and Hakim, I.I., 2018, "Experimental investigation of the operating characteristics of a hybrid loop heat pipe using pump assistance," Applied Thermal Engineering, 130, 10-16. https://doi.org/10.1016/j.applthermaleng.2017.11.007

Singh, R., Akbarzadeh, A., Dixon, C., Mochizuki, M. and Riehl, R.R., 2007, "Miniature Loop Heat Pipe With Flat Evaporator for Cooling Computer CPU," Iee Transactions On Components And Packaging Technologies, 30, 42-49.

https://doi.org/10.1109/TCAPT.2007.892066.

Singh, R., Akbarzadeh, A., and Mochizuki, M., 2009, "Effect of Wick Characteristics on the Thermal Performance of the Miniature Loop Heat Pipe," Journal of Heat Transfer, 131, 082601.

https://doi.org/10.1115/1.3109994

Singh, R., Mochizuki, M., Mashiko, K., and Nguyen, T., 2019 "Data Center Energy Conservation By Heat Pipe Based Precooler System," Frontiers in Heat and Mass Transfer, 10, 24

http://doi.org/10.5098/hmt.13.24.

Singh, R., Nguyen, T., and Mochizuki, M., 2014, "Capillary evaporator development and qualification for loop heat pipes," Applied Thermal Engineering, 63, 406-418.

https://doi.org/10.1016/j.applthermaleng.2013.10.059.

Srimuang, W., and Amatachaya, P., 2012, “A review of the applications of heat pipe heat exchangers for heat recovery," Renewable and Sustainable Energy Reviews, 16, 4303-4315.

https://doi.org/10.1016/j.rser.2012.03.030.
Tang Y., Zhou, R., Lu, L.S., and Xie, Z.C., 2012, “Anti-Gravity Loopshaped heat pipe with graded pore-size wick," Applied Thermal Engineering, 36, 78-86.

https://doi.org/10.1016/j.applthermaleng.2011.12.026

Tang, H., Tang, Y., Yuan, W., Peng, R.T., Lu, L.S., and Wan, Z.P., 2018, "Fabrication and capillary characterization of axially micro-grooved wicks for aluminium flat-plate heat pipes," Applied Thermal Engineering, 129, 907-915.

https://doi.org/10.1016/j.applthermaleng.2017.10.091

Tang, Y., Tang, H., Li, J., Zhang, S., Zhuang, B., and Sun, Y., 2017, "Experimental investigation of capillary force in a novel sintered copper mesh wick for ultra-thin heat pipes," Applied Thermal Engineering, 115, 1020-1030.

https://doi.org/10.1016/j.applthermaleng.2016.12.056

Tharayil, T., Asirvatham, L.G., Ravindran, V., and Wongwises, S., 2016, "Effect of filling ratio on the performance of a novel miniature loop heat pipe having different diameter transport lines," Applied Thermal Engineering, 106, 588-600.

https://doi.org/10.1016/j.applthermaleng.2016.05.125

Tian, W., He, S., Liu, Z.C., and Liu, W., 2019, "Experimental investigation of a miniature loop heat pipe with eccentric evaporator for cooling electronics," Applied Thermal Engineering, 159, 113928. https://doi.org/10.1016/j.applthermaleng.2019.113982

Vershinin, S.V., and Maydanik, Y.F., 2007, "Investigation of pulsations of the operating temperature in a miniature loop heat pipe," International Journal of Heat and Mass Transfer, 50, 5232-5240.

https://doi.org/10.1016/j.ijheatmasstransfer.2007.06.024.

Wang, D.D., Liu, Z.C., He, S., Yang, J.G., and Liu, W., 2015, "Operational characteristics of a loop heat pipe with a flat evaporator and two primary biporous wicks," International Journal of Heat and Mass Transfer, 89, 33-41.

https://doi.org/10.1016/j.ijheatmasstransfer.2015.05.042.

Wang, D.D., Liu, Z.C., Shen, J., Jiang, C., Chen, B.B., Yang, J.G., Tu, Z.K., and Liu, W., 2014, "Experimental study of the loop heat pipe with a flat disk-shaped evaporator," Experimental Thermal and Fluid Science, 57, 157-164.

https://doi.org/10.1016/j.expthermflusci.2014.04.017.

Wang, H.F., Lin, G.P., Shen, X.B., Bai, L.Z., and Wen, D.S., 2019, "Effect of evaporator tilt on a loop heat pipe with non-condensable gas," International Journal of Heat and Mass Transfer, 128, 1072-1080. https://doi.org/10.1016/j.ijheatmasstransfer.2018.09.033.

Wang, S.F., Huo, J.P., Zhang, X.F., and Lin, Z.R., 2012, “Experimental study on operating parameters of miniature loop heat pipe with flat evaporator," Applied Thermal Engineering, 40, 318-325.

https://doi.org/10.1016/j.applthermaleng.2012.02.029.

Wang, S.F., Zhang, W.B., Zhang, X.F., and Chen, J.J., 2011, "Study on start-up characteristics of loop heat pipe under low-power," International Journal of Heat and Mass Transfer, 54, 1002-1007 https://doi.org/10.1016/j.ijheatmasstransfer.2010.10.014.

Wang, X.L., Wei, J.J., Deng, Y.P., Wu, Z., and Sundén, B., 2018, "Enhancement of loop heat pipe performance with the application of micro/nano hybrid structures," International Journal of Heat and Mass Transfer, 127, 1248-1263.

https://doi.org/10.1016/j.ijheatmasstransfer.2018.06.138

Wang, Y.W., Cen, J.W., Jiang, F.M., Cao, W.J., and Guo, J., 2016, “LHP heat transfer performance: A comparison study about sintered copper 
powder wick and copper mesh wick," Applied Thermal Engineering, 92, 104-110.

https://doi.org/10.1016/j.applthermaleng.2015.08.109

Weibel, J.A., Garimella, S.V., and North, M.T., 2010, "Characterization of evaporation and boiling from sintered powder wicks fed by capillary action," International Journal of Heat and Mass Transfer, 53, 42044215.

https://doi.org/10.1016/j.ijheatmasstransfer.2010.05.043

Wu, S.C., Huang, C.J., Chen, S.H., and Chen, Y.M., 2013, "Manufacturing and testing of the double-layer wick structure in a loop heat pipe," International Journal of Heat and Mass Transfer, 56, 709714.

https://doi.org/10.1016/j.ijheatmasstransfer.2012.09.054

Wu, S.C., Wang, D., Lin, W.J., and Chen, Y.M., 2015, "Investigating the effect of powder-mixing parameter in biporous wick manufacturing on enhancement of loop heat pipe performance," International Journal of Heat and Mass Transfer, 89, 460-467.

https://doi.org/10.1016/j.ijheatmasstransfer.2015.05.074

Xin, G.M., Zhang, P., Chen, Y., Cheng, L., Huang, T., and Yin, H.Y., 2018, "Development of composite wicks having different thermal conductivities for loop heat pipes," Applied Thermal Engineering, 136, 229-236.

https://doi.org/10.1016/j.applthermaleng.2018.03.005

Xu, J.L., Ji, X.B., Yang, W.L., and Zhao, Z.W., 2014, "Modulated porous wick evaporator for loop heat pipes: Experiment," International Journal of Heat and Mass Transfer, 72, 163-176.

https://doi.org/10.1016/j.ijheatmasstransfer.2014.01.005

Xu, J.Y., Zhang, L., and Xu, H., 2012, "Performance of LHPs with a novel design evaporator," International Journal of Heat and Mass Transfer, 55, 7005-7014.

https://doi.org/10.1016/j.ijheatmasstransfer.2012.07.013

Yang, C., Song, C.Y., Shang, W., Tao, P., and Deng, T., 2015, "Flexible heat pipes with integrated bioinspired design," Progress in Natural Science: Materials International, 25, 51-57.

https://doi.org/10.1016/j.pnsc.2015.01.011

Yang, K.S., Tu, C.W., Zhang, W.H., Yeh, C.T., and Wang, C.C., 2017, "A novel oxidized composite braided wires wick structure applicable for ultra-thin flattened heat pipes," International Communications in Heat and Mass Transfer, 88, 84-90.

https://doi.org/10.1016/j.icheatmasstransfer.2017.08.014

Yang, K.S., Yang, T.Y., Tu, C.W., Yeh, C.T., and M.T. Lee, 2015, “A novel flat polymer heat pipe with thermal via for cooling electronic devices," Energy Conversion and Management, 100, 37-44. https://doi.org/10.1016/j.enconman.2015.04.063.
Yang, S.R., and Kim, R.H., 1988, "A mathematical model of the pool boiling nucleation site density in terms of the surface characteristics," International Journal of Heat and Mass Transfer. 31 (6), 1127-1135. https://doi.org/10.1016/0017-9310(88)90055-5

Yeh, C.C., Chen, C.N., and Chen, Y.M., 2009, "Heat transfer analysis of a loop heat pipe with biporous wicks," International Journal of Heat and Mass Transfer, 52, 4426-4434.

https://doi.org/10.1016/j.ijheatmasstransfer.2009.03.059

Yodrak, L., Rittidech, S., and Poomsa-ad, N., 2011, "Application of thermosyphon air-preheater for energy thrift from a furnace in a hot forging process," Journal of Mechanical Science and Technology, 25, 193-200.

https://doi.org/10.1007/s12206-010-1118-5.

Young, T., 1805, “An Essay on the Cohesion of Fluids," Philosophical Transactions of the Royal Society of London, 95, 65-87.

https://doi.org/10.1098/rstl.1805.0005

Zhang, X., and Che, H.C., 2013, "Reducing heat loss of fluids in heavy oil wellbore using two-phase closed thermosyphon sucker rod," Energy, 57, 352-358.

https://doi.org/10.1016/j.energy.2013.04.054.

Zhang, X.F., and Wang, S.F., 2011, "Experimental Investigation of Heat Transfer Performance of a Miniature Loop Heat Pipe with Flat Evaporator," Applied Mechanics and Materials, 71-78, 3806-3809. https://doi.org/10.4028/www.scientific.net/AMM.71-78.3806.

Zhang, Y.F., Wang, X.D., Tang, S.C., and F, Z.F. 2010, "Research on Two-Phase Closed Thermosyphon to Improve Fluid Temperature Distribution in Wellbores," Petroleum Science and Technology, 28, 1884-1894. https://doi.org/10.1080/10916466.2010.483445.

Zhou, G.H., Li, J., and Lv, L.C., 2016, “An ultra-thin miniature loop heat pipe cooler for mobile electronics," Applied Thermal Engineering, 109, 514-523. https://doi.org/10.1016/j.applthermaleng.2016.08.138.

Zhou, W., Ling, W.S., Duan, L., Hui, K.S., and Hui, K.N., 2016, "Development and tests of loop heat pipe with multi-layer metal foams as wick structure," Applied Thermal Engineering, 94, 324-330. https://doi.org/10.1016/j.applthermaleng.2015.10.085

Zhu, L., and Yu, J.L., 2016, "Simulation of steady-state operation of an ejector-assisted loop heat pipe with a flat evaporator for application in electronic cooling," Applied Thermal Engineering, 95, 236-246. https://doi.org/10.1016/j.applthermaleng.2015.11.028.

Zuber, N., 1963, "Nucleate boiling. The region of isolated bubbles and the similarity with natural convection," International Journal of Heat and Mass Transfer, 6, 53-60.

https://doi.org/10.1016/0017-9310(63)90029-2. 